
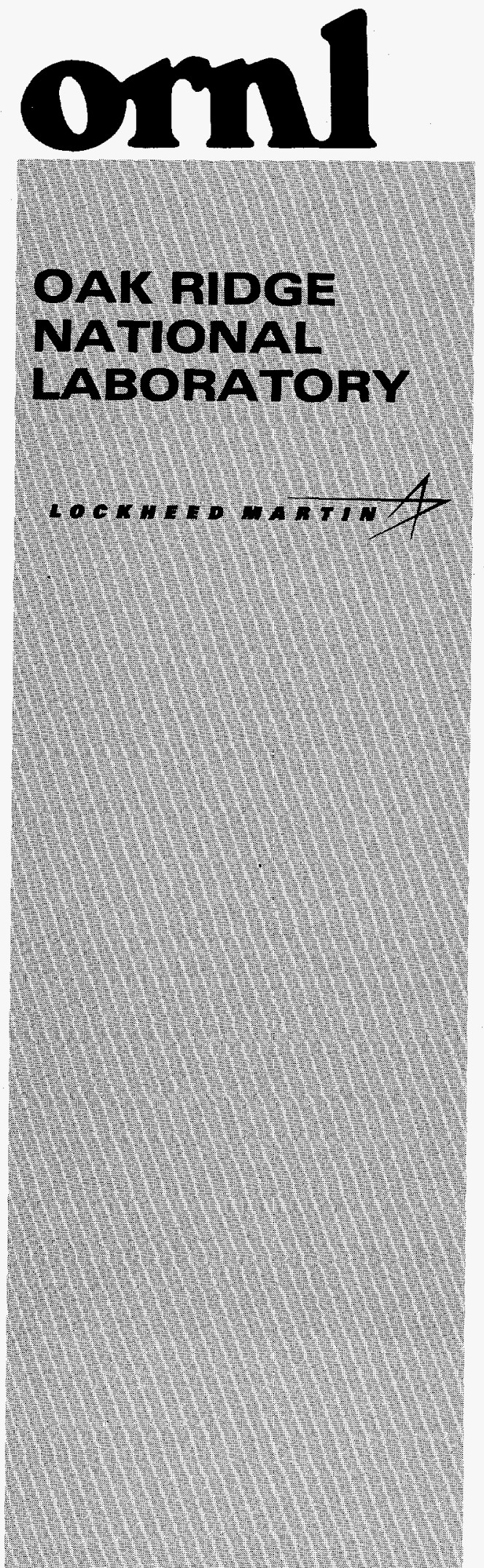

WWAGED WO OPERATED BY LOCKHEED WMATIN ENERGY RESEARCH CORPOALTHOW FOR THE UTTEO STATES DEPATIUENT OF ENERGY

ORNL/TM-13387

\title{
PROCESS STUDY OF POLYCYANATE RESIN FOR WET-FILAMENT WOUND HIGH-STRENGTH COMPOSITES
}

\author{
B. J. Frame \\ Engineering Technology Division \\ Oak Ridge National Laboratory
}

\section{MASTR}

ESTRIBUTION OF NHS DOCUMENT IS UNLIMTES 


\section{DISCLAIMER}

This report was prepared as an account of work sponsored by an agency of the United States Government. Neither the United States Government nor any agency thereof, nor any of their employees, makes any warranty, express or implied, or assumes any legal liability or responsibility for the accuracy, completeness, or usefulness of any information, apparatus, product, or process disclosed, or represents that its use would not infringe privately owned rights. Reference herein to any specific commercial product, process, or service by trade name, trademark, manufacturer, or otherwise, does not necessarily constitute or imply its endorsement, recommendation, or favoring by the United States Government or any agency thereof. The views and opinions of authors expressed herein do not necessarily state or reflect those of the United States Government or any agency thereof. 


\section{DISCLAMMER}

Portions of this docoment may be illegible in electronic image produets. Images are produced from the best availabie original docomentert 


\title{
PROCESS STUDY OF POLYCYANATE RESIN FOR WET-FILAMENT WOUND HIGH-STRENGTH COMPOSITES
}

\author{
B. J. Frame \\ Engineering Technology Division \\ Oak Ridge National Laboratory
}

Prepared by the

Oak Ridge National Laboratory

Oak Ridge, Tennessee 37831-8048

\author{
Managed by \\ LOCKHEED MARTIN \\ ENERGY RESEARCH CORPORATION \\ for the \\ U.S. DEPARTMENT OF ENERGY \\ under contract DE-AC05-960R22464
}




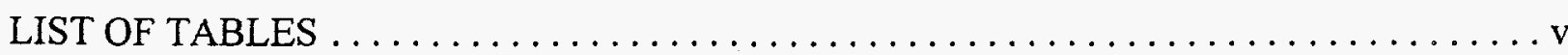

LIST OF FIGURES $\ldots \ldots \ldots \ldots \ldots \ldots \ldots \ldots \ldots \ldots \ldots \ldots \ldots \ldots \ldots \ldots \ldots \ldots \ldots \ldots$

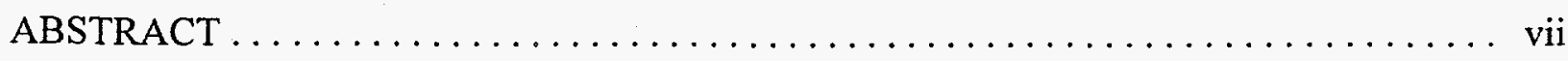

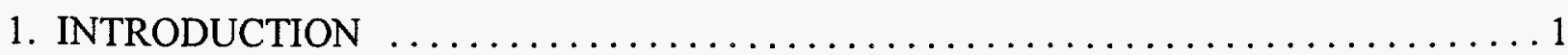

2. T1000G LOT CHARACTERIZATION $\ldots \ldots \ldots \ldots \ldots \ldots \ldots \ldots \ldots \ldots \ldots \ldots \ldots \ldots \ldots \ldots \ldots$

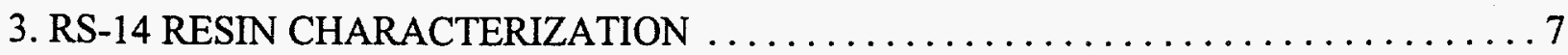

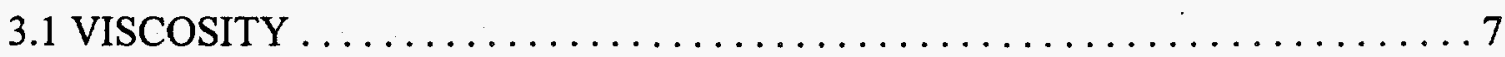

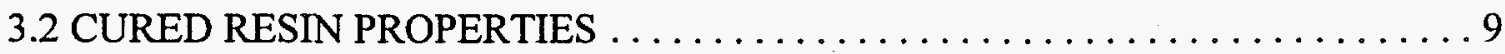

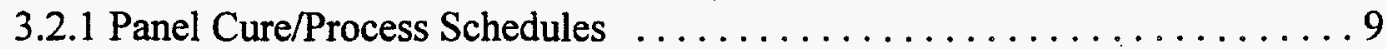

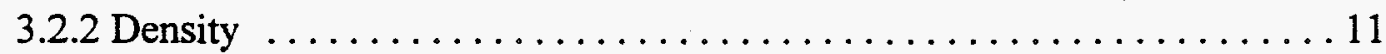

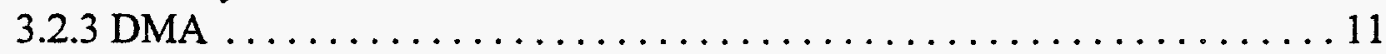

3.2.4 Tensile Properties ................................. 14

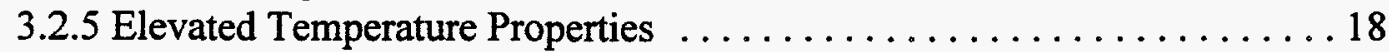

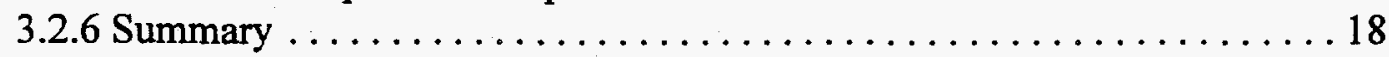

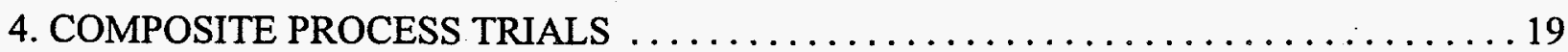

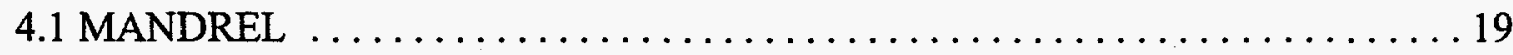

4.2 COMPOSITE CYLINDER FABRICATIONS $\ldots \ldots \ldots \ldots \ldots \ldots \ldots \ldots \ldots \ldots$

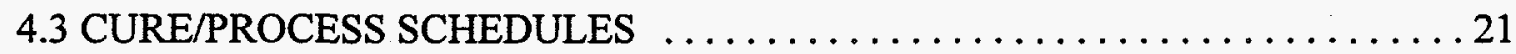

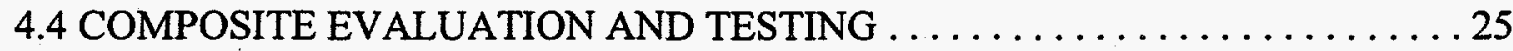

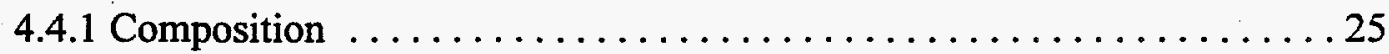

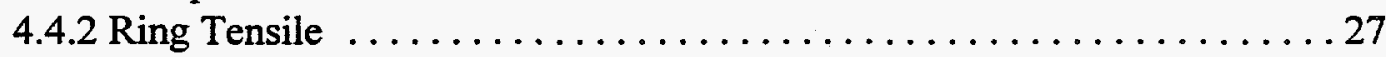

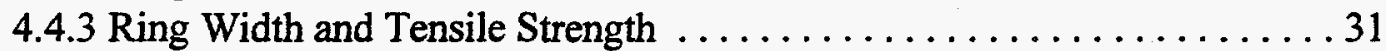

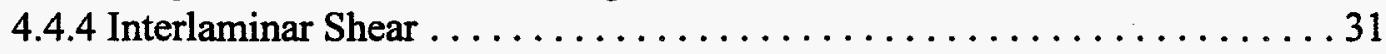

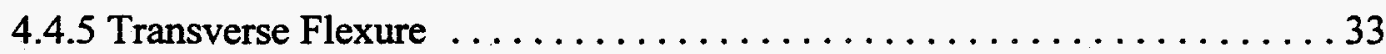

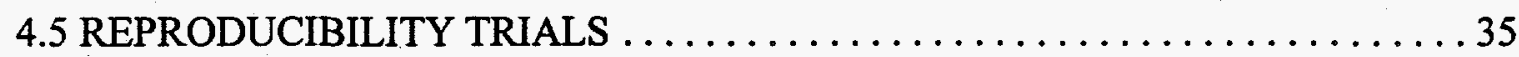

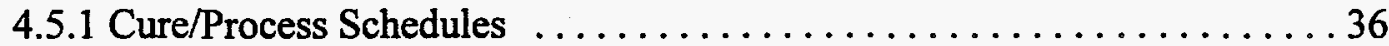

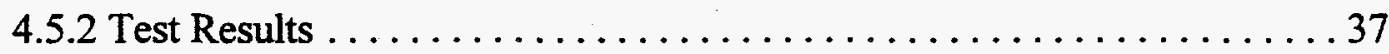

4.6 ELEVATED TEMPERATURE DATA $\ldots \ldots \ldots \ldots \ldots \ldots \ldots \ldots \ldots \ldots \ldots$

4.6.1 Mechanical Properties . . . . . . . . . . . . . . . . . . . . . . 41

4.6.2 Composite DMA ............................. 41

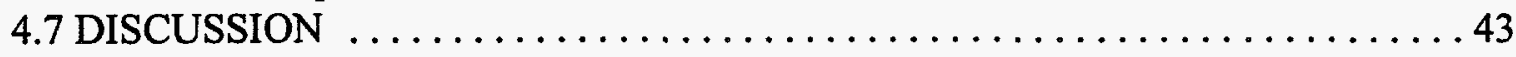

5. CONCLUSIONS AND RECOMMENDATIONS $\ldots \ldots \ldots \ldots \ldots \ldots \ldots \ldots \ldots \ldots$

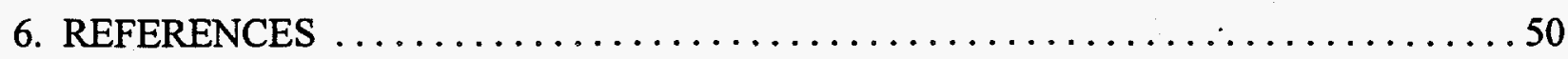

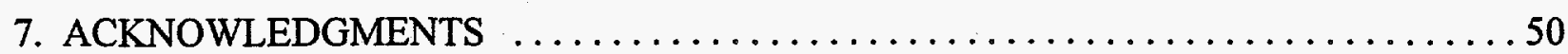


TABLE OF CONTENTS CONTINUED

APPENDIX A. DMA RESULTS OF ISOTHERMAL VISCOSITY TESTS

A1

APPENDIX B. DMA RESULTS FOR NEAT RESIN PANELS

B1 


\section{LIST OF TABLES}

Table 2-1. Toray T1000G lot number 615022 strand tensile properties (start-of-spool). . . . . . 4

Table 2-2. Toray T1000G lot number 615022 strand tensile properties (end-of-spool). . . . . 6

Table 3.2.1-1. RS-14 neat resin properties. .......................... 12

Table 3.2.1-2. RS-14 neat resin tensile properties with temperature. .............. 13

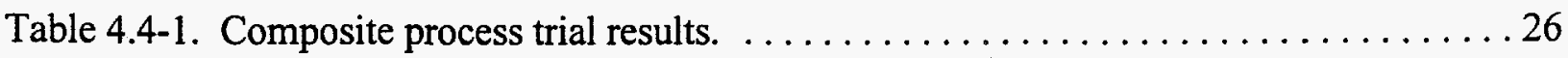

Table 4.4.2-1. T1000G fiber strength translation. ........................ 29

Table 4.4.3-1. Ring width versus tensile properties. . . . . . . . . . . . . . . . . 32

Table 4.5.2-1. Composite process reproducibility results. $\ldots \ldots \ldots \ldots \ldots \ldots \ldots \ldots \ldots$

Table 4.5.2-2. Reproducibility trial $\mathrm{T} 1000 \mathrm{G}$ fiber strength translation. ............. 39

Table 4.6.1-1. Composite properties with temperature. .................. 42

Table 4.6.2-2. Comparison of $\mathrm{T}_{\mathrm{g}}$ from $\mathrm{T} 1000 \mathrm{G} / \mathrm{RS}-14$ composite and RS-14 neat resin $\ldots . .45$ 


\section{LIST OF FIGURES}

Figure 4.6.2-1. DMA result of SR-0019 composite . . . . . . . . . . . . . . . . 44 


\begin{abstract}
Polycyanate (or cyanate ester) resins offer advantages as composite matrices because of their high thermal stability, low outgassing, low water absorption and radiation resistance. This report describes the results of a processing study to develop high-strength hoop-wound composite by the wet-filament winding method using Toray T1000G carbon fiber and YLA RS-14 polycyanate resin as the constituent materials. T1000G/RS-14 composite cylinders were wet-wound and cured using different process schedules and then evaluated for hoop tensile strength and modulus, transverse flexural strength and short beam shear strength. The results of material characterization tests performed on the $\mathrm{T} 1000 \mathrm{G}$ carbon fiber and RS-14 resin constituents used in this study are also presented.
\end{abstract}




\section{INTRODUCTION}

, The Oak Ridge National Laboratory (ORNL) and the Oak Ridge Center for Manufacturing Technology (ORCMT)* are involved in the development of affordable composite structures for military, aerospace and transportation applications. As part of this continuing activity, ORNL and ORCMT evaluate new materials and combinations of materials for use in such applications as pressure vessels, flywheel energy storage systems, and aircraft structures. The determination of the thermomechanical properties of the composite is a key factor in the design of successful high performance applications.

This report documents the development of processing and fabrication methods for wetfilament wound high strength $\mathrm{T} 1000 \mathrm{G} / \mathrm{RS}-14$ polycyanate resin composite. It is a continuation of the work previously performed and reported by ORNL.' The objective of the study was to perform process optimization trials for $\mathrm{T} 1000 \mathrm{G} / \mathrm{RS}-14$ composite and to investigate the effect of alternate cure schedules on composite properties. Material characterization tests and analyses were conducted as well to provide insight into the properties of the T1000G fiber and RS-14 resin constituents.

This report is subdivided into three sections: (1) T1000G Lot Characterization, (2) RS-14 Resin Characterization, and (3) Composite Process Trials. The results of all process trials, analyses and tests are reported and summarized. Recommendations for further study are also included.

\section{T1000G LOT CHARACTERIZATION}

The purpose of this activity was to evaluate the lot of Toray T1000G carbon fiber procured for the composite process trial fabrications with the objectives of verifying properties provided by Toray (the carbon fiber manufacturer) and estimating the lot variability. The data were also necessary to calculate the strength translations obtained from the composite process trials (Sect. 4).

\footnotetext{
*The Oak Ridge Centers for Manufacturing Technology (ORCMT) is jointly managed by the Oak Ridge National Laboratory and Lockheed Martin Energy Systems.
} 
The fiber procurement for this study was made with the stipulation that (1) all of the T1000G be from one lot, and (2) that the lot chosen have a minimum tensile strength of $900 \mathrm{ksi}$ as established by Toray's own internal sampling procedures. The carbon fiber received came from Toray Lot No. 615022. The following is a summary of data provided by Toray on this lot.

$\begin{array}{ll}\text { Description } & \text { Toray T1000GB-12k-40D } \\ \text { Tensile Strength } & 930 \mathrm{ksi} \\ \text { Tensile Modulus } & 43.5 \mathrm{Msi} \\ \text { Elongation } & 2.1 \% \\ \text { Density } & 1.79 \mathrm{~g} / \mathrm{cm}^{3} \\ \text { Weight/Length } & 487 \mathrm{~g} / 10^{3} \mathrm{~m} \\ \text { Sizing } & \text { Type "4" } \\ \text { Size Amount } & 0.7 \%\end{array}$

Lot evaluation was accomplished by measuring strand tensile strength, modulus and fiber weight per unit length from selected spools. Sixty-four 2-kg spools were sampled at the initial ("start") portion of the spool; the remaining fiber near the cardboard core (the "ends") of thirty-two spools used in the fabrication of composite cylinders was retained and similarly sampled.

The strand tensile specimen is a resin-impregnated carbon fiber tow with a 10 in. gage length. The specimens are fabricated by drawing the carbon tow through a heated resin wet-out pot. The strand resin content is controlled by running the fiber through a die or orifice, the size of which determines the strand resin content. The impregnated tow is then wrapped around a dumbbellshaped wooden mandrel at a constant winding advance. After cure, the strands are cut apart off the mandrel and tested.

Strand tensile specimens in this study were impregnated with RS-14 resin at a nominal resin content of $40-45 \mathrm{wt} \%$. The strands were precured four hours at $385^{\circ} \mathrm{F}$ and then allowed to cool to room temperature. The specimens were then removed from the wooden mandrel and postcured four hours at $510^{\circ} \mathrm{F}$.

The specimens were tested to failure at ambient temperature and the break load recorded. Each data set consisted of a minimum of ten specimens. Three specimens from each set were tested using an extensometer to determine the fiber modulus and percent elongation at failure. The secant method was used to calculate the modulus between the range of 3000 to 6000 microstrain. The 
reported impregnated strand strengths were calculated from the break loads and were based on the fiber cross-sectional area only. The cross-sectional area was calculated for each data set from the measured weight per unit length of each section of the spool and vendor-provided density and weight percent sizing information.

Tables 2-1 and 2-2 are a summary, respectively, of T1000G strand tensile data from sampling the start and end portions of the spools. The data show that the average strength from the start or end of the spool ranged between $764 \mathrm{ksi}$ (from the start of spool number 62) to 1,007 ksi (from the start of spool number 64). The global average of the sixty-four data set averages taken from the starts of the spools is $954.3 \mathrm{ksi}$; this is statistically the same as the $953.6 \mathrm{ksi}$ global average of the thirty-two data set averages taken from the spool ends. Comparison of the start data in Table 2-1 with the end data in Table 2-2 for spool numbers 9-40 indicates that the through-spool variability is about the same magnitude as the spool-to-spool variability encountered at both the starts and ends of the carbon fiber packages.

The global tensile strength average for lot number 615022 as measured by ORNL/ORCMT is $954 \mathrm{ksi}$. This is significantly higher than Toray's lot certification number of $930 \mathrm{ksi}$. The disparity is possibly due to differences in the test methods and/or the resin systems used. However, ORNL/ORCMT has measured lower strengths than the Toray lot certification data claimed for previous procurements of $\mathrm{T} 1000 \mathrm{G}$ fiber. This suggests that "better-than-average" material was received in this procurement. It also reflects the need to carefully specify the fiber requirements when making T1000G fiber purchases for strength-critical applications.

The average modulus taken from the start and end of the spools ranges between 37.7 to 42.9 Msi. The average lot modulus is $40.5 \mathrm{Msi}$ and is comparable to other T1000G lots evaluated previously by ORNL/ORCMT. It differs from Toray's $43.5 \mathrm{Msi}$ value, no doubt reflecting differences in the methods that Toray uses to calculate the modulus from the nonlinear carbon fiber stress-strain curve. The measured average elongation of $2.1 \%$ and $0.488 \mathrm{~g} / \mathrm{m}$ weight per unit length are, however, comparable to Toray's data. 
Table 2-1. Toray T1000G lot number 615022 strand tensile properties (start-of-spool).

\begin{tabular}{|c|c|c|c|c|c|c|c|}
\hline $\begin{array}{c}\text { SPOOL } \\
\text { NO. }\end{array}$ & $\begin{array}{c}\text { Fiber } W T \text {. / length } \\
(\mathrm{gm} / \mathrm{m})\end{array}$ & $\begin{array}{c}\text { NO. OF } \\
\text { SPECIMENS }\end{array}$ & $\begin{array}{l}\text { UTS } \\
\text { (ksi) }\end{array}$ & $\begin{array}{c}\text { ST.DEV. } \\
\text { (ksi) }\end{array}$ & $\begin{array}{c}\% \bar{C} . \\
\text { VARIATION }\end{array}$ & $\begin{array}{l}\text { MODULUS } \\
\text { (Msi) }\end{array}$ & $\begin{array}{c}\text { ELONG } \\
(\%) \\
\end{array}$ \\
\hline 1 & 0.488 & 10 & 982.6 & 22.4 & 2.3 & 40.5 & 2.2 \\
\hline 2 & 0.492 & 13 & 955.2 & 24.8 & 2.6 & 40.2 & 2.2 \\
\hline 3 & 0.485 & 14 & 933.8 & 49.1 & 5.3 & 40.5 & 2.1 \\
\hline 4 & 0.490 & 13 & 967.4 & 27.7 & 2.9 & 40.4 & 2.2 \\
\hline 5 & 0.494 & 16 & 932.1 & 41.8 & 4.5 & 40.9 & 2.1 \\
\hline 6 & 0.487 & 14 & 947.8 & 59.0 & 6.2 & 41.0 & 2.2 \\
\hline 7 & 0.490 & 11 & 965.7 & 46.0 & 4.8 & 40.7 & 2.1 \\
\hline 8 & 0.490 & 13 & 954.9 & 40.2 & 4.2 & 41.0 & 2.2 \\
\hline 9 & 0.490 & 13 & 959.3 & 43.9 & 4.6 & 42.9 & 2.0 \\
\hline 10 & 0.490 & 15 & 890.6 & 73.3 & 8.2 & 40.7 & 1.9 \\
\hline 11 & 0.491 & 12 & 947.6 & 75.9 & 8.0 & 40.4 & 2.2 \\
\hline 12 & 0.490 & 115 & 970.0 & 32.2 & .3 .8 & 40.5 & 2.1 \\
\hline 13 & 0.489 & 16 & 938.8 & 52.2 & 5.6 & 40.2 & 2.0 \\
\hline 14 & 0.487 & 15 & 926.8 & 59.9 & 6.5 & 41.0 & 2.0 \\
\hline 15 & 0.481 & 18 & 927.9 & 57.6 & 6.2 & $40: 4$ & 2.1 \\
\hline 16 & 0.493 & 16 & 950.6 & 46.3 & 4.9 & 40.5 & 2.1 \\
\hline 17 & 0.485 & 12 & 978.3 & 33.5 & 3.4 & 40.1 & 2.2 \\
\hline 18 & 0.482 & 13 & 994.2 & 18.6 & 1.9 & 40.9 & 2.2 \\
\hline .19 & 0.483 & 15 & 985.5 & 21.6 & 2.2 & 40.2 & 2.2 \\
\hline 20 & 0.486 & 14 & 938.2 & 53.4 & 5.7 & 41.1 & 2.2 \\
\hline 21 & 0.490 & 16 & 910.9 & 53.8 & 5.9 & 40.2 & 2.0 \\
\hline 22 & 0.483 & 12 & 976.4 & 53.2 & 5.5 & 40.6 & 2.1 \\
\hline 23 & 0.487 & 15 & 929.0 & 45.4 & 4.9 & 40.2 & 2.1 \\
\hline 24 & 0.483 & 16 & 985.6 & 37.1 & 3.8 & 40.3 & 2.1 \\
\hline 25 & 0.491 & 15 & 910.7 & 108.9 & 12.0 & 41.6 & 1.9 \\
\hline 26 & 0.484 & 16 & 993.2 & 72.2 & 7.3 & 40.9 & 2.2 \\
\hline 27 & 0.492 & 15 & 934.1 & 100.2 & 10.7 & 40.8 & 1.8 \\
\hline 28 & 0.490 & 16 & 967.1 & 58.4 & 6.0 & 40.4 & 2.1 \\
\hline 29 & 0.492 & 17 & 981.5 & 41.0 & 4.2 & 40.7 & 2.2 \\
\hline 30 & 0.486 & 15 & $1,000.8$ & 28.9 & 2.9 & 40.5 & 2.1 \\
\hline 31 & 0.487 & 14 & 992.8 & 53.1 & 5.3 & 41.6 & 2.1 \\
\hline 32 & 0.485 & 16 & 983.1 & 31.0 & 3.2 & 40.4 & 2.1 \\
\hline 33 & 0.484 & 15 & 968.9 & 42.7 & 4.4 & 39.8 & 2.1 \\
\hline 34 & 0.493 & 14 & 976.8 & 49.0 & 5.0 & 41.0 & 2.1 \\
\hline 35 & 0.491 & 16 & 957.7 & 62.1 & 6.5 & 41.2 & 2.1 \\
\hline 36 & 0.491 & 16 & 984.5 & 45.9 & 4.7 & 41.0 & 2.1 \\
\hline 37 & 0.490 & 16 & 976.2 & 31.5 & 3.2 & 40.9 & 2.2 \\
\hline 38 & 0.490 & 16 & 942.4 & 29.5 & 3.1 & 40.3 & 2.1 \\
\hline 39 & 0.490 & 11 & 957.2 & 37.2 & 3.9 & 40.5 & 2.1 \\
\hline 40 & 0.487 & 14 & 960.0 & 39.4 & 4.1 & 41.1 & 2.1 \\
\hline 41 & 0.491 & 17 & 953.2 & 39.7 & 4.2 & 39.6 & 2.1 \\
\hline 42 & 0.488 & 15 & 959.9 & 59.8 & 6.2 & 40.2 & 2.2 \\
\hline 43 & 0.484 & 16 & 984.1 & 27.9 & 2.8 & 39.6 & 2.2 \\
\hline
\end{tabular}


Table 2-1. (Continued.)

\begin{tabular}{|c|c|c|c|c|c|c|c|}
\hline $\begin{array}{c}\text { SPOOL } \\
\text { NO. }\end{array}$ & $\begin{array}{c}\text { Fiber WT. / length } \\
(\mathrm{gm} / \mathrm{m})\end{array}$ & $\begin{array}{c}\text { NO. OF } \\
\text { SPECIMENS }\end{array}$ & $\begin{array}{l}\text { UTS } \\
\text { (ksi) }\end{array}$ & $\begin{array}{c}\text { ST. DEV. } \\
\text { (ksi) }\end{array}$ & $\begin{array}{c}\% \mathrm{C} . \\
\text { VARIATION }\end{array}$ & $\begin{array}{l}\text { MODULUS } \\
\text { (Msi) }\end{array}$ & $\begin{array}{c}\text { ELONG } \\
(\%)\end{array}$ \\
\hline 44 & 0.488 & 18 & 954.2 & 40.3 & 4.2 & 39.7 & 2.2 \\
\hline 45 & 0.487 & 19 & 931.4 & 51.5 & 5.5 & 39.7 & 2.1 \\
\hline 46 & 0.492 & 18 & 965.2 & 39.7 & 4.1 & 40.0 & 2.2 \\
\hline 47 & 0.481 & 15 & 919.4 & 34.2 & 3.7 & 39.3 & 2.1 \\
\hline 48 & 0.486 & 15 & 980.1 & 39.2 & 4.0 & 39.8 & 2.2 \\
\hline 49 & 0.491 & 13 & 946.6 & 73.3 & 7.8 & 40.4 & 2.1 \\
\hline 50 & 0.494 & 16 & 957.0 & 50.4 & 5.3 & 42.1 & 2.0 \\
\hline 51 & 0.493 & 16 & 968.8 & 37.2 & 3.8 & 42.7 & 2.1 \\
\hline 52 & 0.490 & 14 & 943.5 & 35.2 & 3.7 & 41.0 & 2.1 \\
\hline 53 & 0.488 & 16 & 995.6 & 33.3 & 3.4 & 41.2 & 2.1 \\
\hline 54 & 0.490 & 16 & 969.1 & 40.3 & 4.2 & 41.4 & 2.2 \\
\hline 55 & 0.490 & 11 & 928.3 & 56.5 & 6.1 & 41.3 & 2.1 \\
\hline 56 & 0.491 & 14 & 962.1 & 46.0 & 4.8 & 41.0 & 2.1 \\
\hline 57 & 0.493 & 16 & 877.7 & 91.6 & 10.4 & 40.9 & 2.0 \\
\hline 58 & 0.491 & 17 & 954.3 & 38.6 & 4.1 & 41.0 & 2.1 \\
\hline 59 & 0.485 & 16 & 945.4 & 45.8 & 4.8 & 41.5 & 2.1 \\
\hline 60 & 0.487 & 15 & 932.6 & 75.8 & 8.1 & 41.1 & 2.1 \\
\hline 61 & 0.490 & 18 & 953.6 & 110.9 & 11.6 & 40.0 & 2.2 \\
\hline 62 & 0.486 & 11 & 763.9 & 103.6 & 13.6 & 37.7 & 2.1 \\
\hline 63 & 0.486 & 15 & 985.2 & 49.1 & 5.0 & 41.6 & 2.1 \\
\hline 64 & 0.489 & 14 & $1,007.3$ & 34.6 & 3.4 & 39.7 & 2.3 \\
\hline TOTAL & 0.488 & 951 & 954.3 & 35.6 & 3.7 & 40.6 & 2.1 \\
\hline
\end{tabular}


Table 2-2. Toray T1000G lot number 615022 strand tensile properties (end-of-spool).

\begin{tabular}{|c|c|c|c|c|c|c|c|}
\hline $\begin{array}{l}\text { SPOOL } \\
\text { NO. }\end{array}$ & $\begin{array}{l}\text { Fiber WT. Rlength } \\
(\mathrm{gm} / \mathrm{m})\end{array}$ & $\begin{array}{c}\text { NO OF } \\
\text { SPECIMENS }\end{array}$ & $\begin{array}{l}\text { UTS } \\
\text { (ksi) }\end{array}$ & $\begin{array}{c}\text { ST. DEV. } \\
\text { (ksi) }\end{array}$ & $\begin{array}{c}\% \mathrm{C} . \\
\text { VARIATION }\end{array}$ & $\begin{array}{c}\text { MODULUS } \\
\text { (Msi) }\end{array}$ & $\begin{array}{c}\text { ELONG } \\
(\%)\end{array}$ \\
\hline 9 & 0.492 & 17 & 971.1 & 25.9 & 2.7 & 40.8 & 2.1 \\
\hline 10 & 0.488 & 15 & 927.3 & 40.9 & 4.4 & 40.6 & 2.1 \\
\hline 11 & 0.490 & 14 & 965.0 & 38.2 & 4.0 & 40.7 & 2.1 \\
\hline 12 & 0.490 & 15 & 972.2 & 27.7 & 2.9 & 40.6 & 2.2 \\
\hline 13 & 0.490 & 11 & 984.3 & 24.3 & 2.5 & 41.3 & 2.2 \\
\hline 14 & 0.489 & 13 & 935.5 & 54.7 & 5.9 & 41.3 & 2.0 \\
\hline 15 & 0.483 & 16 & 961.8 & 37.7 & 3.9 & 40.6 & 2.2 \\
\hline 16 & 0.492 & 14 & 955.3 & 32.0 & 3.4 & 40.7 & 2.2 \\
\hline 17 & 0.486 & 13 & 944.7 & 40.8 & 4.3 & 40.3 & 2.1 \\
\hline 18 & 0.483 & 12 & 964.5 & 55.3 & 5.7 & 39.8 & 2.2 \\
\hline 19 & 0.479 & 15 & 970.4 & 26.4 & 2.7 & 40.9 & 2.2 \\
\hline 20 & 0.484 & 16 & 967.6 & 67.3 & 7.0 & 41.0 & 2.2 \\
\hline 21 & 0.491 & 14 & 943.9 & 51.9 & 5.5 & 40.1 & 2.1 \\
\hline 22 & 0.484 & 14 & 991.5 & 46.0 & 4.6 & 40.6 & 2.2 \\
\hline 23 & 0.490 & 13 & 984.5 & 73.6 & 7.5 & 41.3 & 2.1 \\
\hline 24 & 0.484 & 16 & 937.8 & 85.2 & 9.1 & 39.6 & 2.2 \\
\hline 25 & 0.492 & 13 & 941.4 & 38.3 & 4.1 & 41.1 & 2.1 \\
\hline 26 & 0.484 & 17 & 955.2 & 39.3 & 4.1 & 40.6 & 2.2 \\
\hline 27 & 0.493 & 15 & 950.9 & 29.5 & 3.1 & 41.5 & 2.0 \\
\hline 28 & 0.491 & 15 & 943.6 & 36.3 & 3.9 & 40.7 & 2.1 \\
\hline 29 & 0.494 & 16 & 934.7 & 34.4 & 3.7 & 40.4 & 2.1 \\
\hline 30 & 0.486 & 14 & 943.9 & 39.7 & 4.2 & 40.3 & 2.0 \\
\hline 31 & 0.486 & 15 & 951.1 & 42.2 & 4.4 & 42.1 & 2.2 \\
\hline 32 & 0.484 & 15 & 949.4 & 45.6 & 4.8 & 40.0 & 2.0 \\
\hline 33 & 0.483 & 15 & 919.9 & 48.9 & 5.3 & 38.7 & 2.2 \\
\hline 34 & 0.493 & 13 & 971.1 & 37.2 & 3.8 & 39.5 & 2.2 \\
\hline 35 & 0.490 & 14 & 899.9 & 57.2 & 6.4 & 39.4 & 2.1 \\
\hline 36 & 0.492 & 15 & 954.8 & 35.1 & 3.7 & 42.2 & 2.2 \\
\hline 37 & 0.490 & 13 & 955.9 & 60.6 & 6.3 & 40.2 & 2.2 \\
\hline 38 & 0.490 & 15 & 956.3 & 29.0 & 3.0 & 39.7 & 2.2 \\
\hline 39 & 0.491 & 12 & 972.9 & 35.2 & 3.6 & 39.9 & 2.2 \\
\hline 40 & 0.488 & 16 & 937.1 & 65.8 & 7.0 & 40.0 & 2.0 \\
\hline TOTAL & 0.488 & 4651 & 953.6 & 19.6 & 2.1 & 40.5 & 2.1 \\
\hline
\end{tabular}


Of the sixty-four spools sampled, spool number 62 had both the lowest average tensile strength (763.9 ksi) and modulus (37.7 Msi). It is not known whether these data were representative of the whole spool or just the small portion sampled in this study. The spool was separated from the remainder of the lot and not used in any of the process trials.

It was not possible to perform a formal and complete statistical analysis on the strand strength data on a spool-to-spool and through-spool basis because the scope of the T1000G fiber characterization study was limited. However, a thorough statistical analysis of the data is recommended because the strength and variability of the T1000G fiber controls the strength and uniformity of the properties of the composite hardware. These analyses can also give the design community a baseline for establishing a quality assurance program for making future $\mathrm{T} 1000 \mathrm{G}$ fiber procurements.

\section{RS-14 RESIN CHARACTERIZATION}

The RS-14 resin is a polycyanate resin blend from YLA Incorporated. At the time of this study, the vendor indicated that little material testing had been performed on this resin system. The purpose of this activity was therefore to characterize the neat RS-14 resin and to obtain specific process and material property data pertinent to the fabrication and testing of composite hardware. These tests and analyses also complement work performed as part of the composite process trials (Sect. 4).

\subsection{VISCOSITY}

From a manufacturing standpoint, it is important to characterize the viscosity of a neat resin as a function of both time and temperature. This information establishes the upper resin bath temperature for wet-filament winding that will effectively impregnate the carbon fiber bundle while maintaining a sufficient pot life to wind large parts. At higher temperatures, viscosity data with time and temperature yields information on the gel time of the resin. Gel time data set the upper temperature limits for the mandrel during winding to ensure that the resin does not set up too soon, preventing effective compaction and resin bleedout. This information also establishes a minimum time the mandrel must be rotated at a given temperature to prevent the composite from sagging 
during cure.

The resin viscosity measurements were accomplished using a Rheometrics Dynamic Spectrometer and 25-mm parallel plates set at a $0.5-\mathrm{mm}$ gap. RS-14 resin procured for this study (YLA Reference No. FB3K702, manufactured September 26, 1995) was tested at six temperatures at $10 \mathrm{rad} / \mathrm{s}$ frequency and $500 \%$ strain. Testing was under isothermal conditions for as long as eight hours or until the resin gelled. Resin gelation was defined as the point when tan delta was greater than 1.0.

The six test temperatures were $170^{\circ} \mathrm{F}, 200^{\circ} \mathrm{F}, 230^{\circ} \mathrm{F}, 260^{\circ} \mathrm{F}, 290^{\circ} \mathrm{F}$, and $310^{\circ} \mathrm{F}$. The $170^{\circ} \mathrm{F}$ temperature is the lower boundary for the resin bath temperature based on viscosity with temperature data provided by YLA Incorporated. (Below $170^{\circ} \mathrm{F}$, the RS-14 resin system is too viscous for successful wet-winding with carbon fiber). The $310^{\circ} \mathrm{F}$ temperature is an upper bound based on reasonable expectations of the heating capability of the internally heated steel mandrel and on the gel time information provided by YLA Incorporated.

Appendix A contains the DMA results of the six isothermal viscosity tests. A summary of the data is as follows:

$170^{\circ} \mathrm{F}$ The viscosity rose slightly from 0.53 poise to 0.73 poise in $8 \mathrm{hr}$.

$200^{\circ} \mathrm{F}$ The viscosity rose steadily from 0.28 poise to 0.88 poise in $8 \mathrm{hr}$.

$230^{\circ} \mathrm{F}$ The viscosity rose steadily from 0.15 poise to 7.14 poise in $8 \mathrm{hr}$.

$260^{\circ} \mathrm{F}$ The resin gelled in $264 \mathrm{~min}(4.4 \mathrm{hr})$. The initial viscosity was 0.23 poise and the final viscosity was 6836 poise.

$290^{\circ} \mathrm{F}$ The resin gelled in $80 \mathrm{~min}$. The initial viscosity was 0.14 poise and the final viscosity was 2045 poise.

$310^{\circ} \mathrm{F}$ The resin gelled in $40 \mathrm{~min}$. The initial viscosity was 0.29 poise and the final viscosity was 3091 poise.

The data indicate that the RS-14 resin should be an excellent wet-winding resin in the vicinity of $170^{\circ} \mathrm{F}$ because of its low viscosity and stability. The minimum temperature needed to gel the resin in a four hour period is approximately $260^{\circ} \mathrm{F}$. The resin gels quickly (less than an hour) when the temperature is in the vicinity of $310^{\circ} \mathrm{F}$. 


\subsection{CURED RESIN PROPERTIES}

Determination of cured resin properties was performed because the neat resin is a vital component of the composite, yet very little physical, mechanical, and thermal property data were available from YLA Incorporated. The impact of alternate cure schedules on RS-14 resin properties was evaluated by casting nominal $1 / 8$ in. thick neat resin panels using cure schedules that correspond to those conducted during the composite process trials (Sect. 4). The resin panels were cut into

specimens and tested for density, $T_{g}$, shear modulus using Dynamic Mechanical Analysis (DMA), and tensile properties (strength, modulus, and elongation). Tensile properties were measured at both ambient and elevated $\left(275^{\circ} \mathrm{F}\right)$ temperatures.

\subsubsection{Panel Cure/Process Schedules}

Five cure or process cycles were evaluated in this study. These panels were cast by YLA Incorporated and cured in 80 psi air pressure in an autoclave per the following schedules: Panel 342:

$3^{\circ} \mathrm{F} / \mathrm{min}$ ramp to $270^{\circ} \mathrm{F}$ and hold for $4 \mathrm{hr}$.

$2^{\circ} \mathrm{F} / \mathrm{min}$ ramp to $510^{\circ} \mathrm{F}$ and hold for $4 \mathrm{hr}$.

Return to ambient temperature $\left(5^{\circ} \mathrm{F} / \mathrm{min}\right.$ maximum cool down rate)

Panels 344, 345, 346, and 347:

$3^{\circ} \mathrm{F} / \mathrm{min}$ ramp to $380^{\circ} \mathrm{F}$ and hold for $3 \mathrm{hr}$.

$2^{\circ} \mathrm{F} / \mathrm{min}$ ramp to $510^{\circ} \mathrm{F}$ and hold for $4 \mathrm{hr}$.

Return to ambient temperature $\left(5^{\circ} \mathrm{F} / \mathrm{min}\right.$ maximum cool down rate)

Post-processing of Panels 346 and 347 (conducted by ORNL/ORCMT in convection air oven):

Panels laid on flat metal surface.

$2^{\circ} \mathrm{F} / \mathrm{min}$ ramp to $510^{\circ} \mathrm{F}$ and hold for $4 \mathrm{hr}$.

Return to ambient temperature $\left(5^{\circ} \mathrm{F} / \mathrm{min}\right.$ maximum cool down rate)

$2^{\circ} \mathrm{F} / \mathrm{min}$ ramp to $510^{\circ} \mathrm{F}$ and hold for $4 \mathrm{hr}$.

Return to ambient temperature $\left(5^{\circ} \mathrm{F} / \mathrm{min}\right.$ maximum cool down rate)

The post-processing of Panels 346 and 347 was to determine the effects of multiple postcure cycles on cured resin properties. Multiple postcure cycles may be encountered in the fabrication of 
thick composites that are wound and cured in increments. Composite hardware that is coated or bonded with polycyanate (or other high temperature cure) adhesives and coatings may also receive additional postcure cycles.

Panel 348:

$3^{\circ} \mathrm{F} / \mathrm{min}$ ramp to $380^{\circ} \mathrm{F}$ and hold for $3 \mathrm{hr}$.

Return to ambient temperature $\left(5^{\circ} \mathrm{F} / \mathrm{min}\right.$ maximum cool down rate)

Panel removed from mold; placed between metal plates and wrapped with fiberglass.

Panel postcured in same autoclave cycle as Panel 350)

Panel 350 (and postcure of Panel 348)

$3^{\circ} \mathrm{F} / \mathrm{min}$ ramp to $380^{\circ} \mathrm{F}$ followed by $2^{\circ} \mathrm{F} / \mathrm{min}$ ramp to $510^{\circ} \mathrm{F}$ and hold for $4 \mathrm{hr}$.

Return to ambient temperature $\left(5^{\circ} \mathrm{F} / \mathrm{min}\right.$ maximum cool down rate)

In addition to the above, the following resin panels, (all of which were cured in a convection air oven), were included in the test matrix.

Panel 125:

$4 \mathrm{hr}$ at $350^{\circ} \mathrm{F}$

Panel removed from mold; placed between metal plates and wrapped with fiberglass.

$4 \mathrm{hr}$ at $475^{\circ} \mathrm{F}$

(Panel 125 was fabricated by YLA Incorporated for evaluation. Its uppermost postcure temperature is $35^{\circ} \mathrm{F}$ lower than that of the previous seven panels.)

Panel GL-10/20/95

$5^{\circ} \mathrm{F} / \mathrm{min}$ ramp to $380^{\circ} \mathrm{F}$ and hold for $4 \mathrm{hr}$.

Return to ambient temperature $\left(5^{\circ} \mathrm{F} / \mathrm{min}\right.$ maximum cool down rate)

Panel removed from mold and laid on flat metal surface.

$2^{\circ} \mathrm{F} / \mathrm{min}$ ramp to $510^{\circ} \mathrm{F}$ and hold for $4 \mathrm{hr}$.

Return to ambient temperature $\left(5^{\circ} \mathrm{F} / \mathrm{min}\right.$ maximum cool down rate)

(Panel GL-10/20/95 was cast and cured during the fabrication of the T1000G strand tensile specimens in Sect. 2.) 
The results of the density, DMA and room temperature tensile testing are summarized in Table 3.2.1-1. Panels 345 and 347 were tested for tensile properties only at $275^{\circ} \mathrm{F}$, and the data are summarized in Table 3.2.1-2. The test methods and results are discussed in the following sections.

\subsubsection{Density}

Density measurements were made via ASTM D792 (Tests for Specific Gravity and Density of Plastics by Displacement) with a 2 in. $\mathrm{x} 3$ in. section of resin panel. The resin density for all of the panels is on the order of $1.20 \mathrm{~g} / \mathrm{cm}^{3}$. This agrees with information provided by YLA Incorporated. Although Panels 125 and GL-10/20/95 were cured in an oven, their measured densities are comparable to those of the panels cured in an autoclave, indicating that porosity in these panels is not significant.

\subsubsection{DMA}

DMA was accomplished using a Rheometrics Dynamic Spectrometer with the rectangular torsion test geometry. The samples were tested with a fixed frequency of $6.28 \mathrm{rad} / \mathrm{s}$ and a commanded strain of $0.03 \%$. The testing was accomplished by performing a temperature sweep of $5^{\circ} \mathrm{C}$ steps from room temperature to $150^{\circ} \mathrm{C}\left(302^{\circ} \mathrm{F}\right)$ and soaking for 3 minutes at each temperature prior to taking the measurement. From $150^{\circ}$ to $350^{\circ} \mathrm{C}$ the specimen was tested using a temperature sweep of $3^{\circ} \mathrm{C}$ steps with a 2 minute soak time at each temperature. The data recorded at each temperature includes G', G" and tan delta. Appendix B contains the DMA results of the resin panels. The shear modulus data reported in Table 3.2.1-1 are of the $G$ ' storage (elastic component) modulus taken at room temperature. The $T_{\mathrm{g}}$ was calculated from the $G^{\prime}$ versus temperature curve using the line-fit intersection method. In this method, the straight line portions before and after the "knee" in the curve are extrapolated and the $T_{g}$ is interpreted as the point on the temperature axis at which the two lines intersect.

The $T_{g}$ data show surprising variability considering that Panels $342,344,346,348,350$ and GL-10/20/95 were all taken to the same $510^{\circ} \mathrm{F}$ postcure temperature. Based on the data from Panels 342 and 348 , the $T_{g}$ of the RS- 14 resin can be as high at $510^{\circ}-512^{\circ} \mathrm{F}$. 
Table 3.2.1-1. RS-14 neat resin properties.

\begin{tabular}{|c|c|c|c|c|c|c|}
\hline \multirow[t]{2}{*}{ Panel } & \multirow{2}{*}{$\begin{array}{c}\text { Density } \\
(\mathrm{gm} / \mathrm{cm} 3)\end{array}$} & \multicolumn{3}{|c|}{ Tensile Properties * } & \multirow{2}{*}{$\begin{array}{c}\mathbf{G}^{\prime} @ 77^{\circ} \mathbf{F} \\
\text { (ksi) }\end{array}$} & \multirow{2}{*}{$\begin{array}{l}\mathrm{Tg} \\
\left({ }^{\circ} \mathrm{F}\right) \\
\end{array}$} \\
\hline & & Strength (psi) & Modulus (ksi) & Elongation (\%) & & \\
\hline \multirow[t]{2}{*}{342} & 1.1986 & 11,333 & 419.3 & 4.1 & 153.3 & 507 \\
\hline & & (11.8) & $(2.8)$ & $(20.3)$ & & \\
\hline \multirow[t]{2}{*}{344} & 1.1998 & 11,133 & 410.6 & 4.0 & 157.6 & 495 \\
\hline & & $(17.5)$ & $(1.8)$ & $(27.3)$ & & \\
\hline \multirow[t]{2}{*}{346} & 1.2077 & 9,295 & 441.8 & 2.5 & 173.3 & 458 \\
\hline & & $(9.3)$ & $(2.4)$ & (12.5) & & \\
\hline \multirow[t]{2}{*}{348} & 1.2028 & 10,214 & 415.6 & 3.3 & 155.6 & 512 \\
\hline & & (9.6) & $(1.6)$ & (14.8) & & \\
\hline \multirow[t]{2}{*}{350} & 1.2059 & 9,708 & 430.5 & 2.9 & 155.2 & 487 \\
\hline & & $(7.6)$ & (2.3) & (11.3) & & \\
\hline \multirow[t]{2}{*}{125} & 1.2039 & 9,383 & 440.2 & 2.8 & 168.4 & 451 \\
\hline & & $(17.4)$ & $(3.4)$ & (23.5) & & \\
\hline GL-10/20/95 & 1.2054 & $\begin{array}{l}8,910 \\
(12.9)\end{array}$ & $\begin{array}{c}418.9 \\
(2.8)\end{array}$ & $\begin{array}{c}2.6 \\
(16.6)\end{array}$ & 172.7 & 455 \\
\hline
\end{tabular}

( ) Number in parentheses is percent coefficient of variation.

* Number of specimens: 9-10 
Table 3.2.1-2. RS-14 neat resin tensile properties with temperature.

\begin{tabular}{|c|c|c|c|c|c|c|}
\hline \multirow[t]{2}{*}{ Panel } & \multicolumn{2}{|c|}{ Strength (psi) } & \multicolumn{2}{|c|}{ Modulus (ksi) } & \multicolumn{2}{|c|}{ Elongation (\%) } \\
\hline & $76^{\circ} \mathrm{F}$ & $275^{\circ} \mathrm{F}$ & $76^{\circ} \mathrm{F}$ & $275^{\circ} \mathrm{F}$ & $76^{\circ} \mathrm{F}$ & $275^{\circ} \mathrm{F}$ \\
\hline $344 / 345$ (a) & $\begin{array}{c}11,133 \\
(17.5)\end{array}$ & $\begin{array}{c}9,247 \\
(3.3)\end{array}$ & $\begin{array}{c}410.6 \\
(1.8)\end{array}$ & $\begin{array}{c}301.3 \\
(2.4)\end{array}$ & $\begin{array}{c}4.0 \\
(27.3)\end{array}$ & $\begin{array}{c}6.1 \\
(22.7)\end{array}$ \\
\hline $346 / 347$ (b) & $\begin{array}{c}9,295 \\
(9.3) \\
\end{array}$ & $\begin{array}{c}5,923 \\
(5.6) \\
\end{array}$ & $\begin{array}{c}441.8 \\
(2.4) \\
\end{array}$ & $\begin{array}{c}347.8 \\
(0.8)\end{array}$ & $\begin{array}{c}2.5 \\
(12.5)\end{array}$ & $\begin{array}{l}1.9 \\
(6.2)\end{array}$ \\
\hline
\end{tabular}

( ) Number in parenthese is percent coefficient of variation.

(a) $380^{\circ} \mathrm{F}$ precure followed by ramp to $510^{\circ} \mathrm{F}$ postcure.

(b) Same as (a) except received two additional postcure cycles at $510^{\circ} \mathrm{F}$. 
The $\mathrm{T}_{\mathrm{g}}$ of Panel 125 , which was cured to $475^{\circ} \mathrm{F}$, is only $451^{\circ} \mathrm{F}$. This suggests that the RS-14 resin requires the higher $510^{\circ} \mathrm{F}$ postcure temperature to achieve its maximum $\mathrm{T}_{\mathrm{g}}$.

Panels 344 and 346 were cured side by side in the same autoclave cycle, but panel 346 has a $T_{g}$ of only $458^{\circ} \mathrm{F}$. This is particularly surprising considering that Panel 346 received two additional postcure cycles at $510^{\circ} \mathrm{F}$ which did not serve to increase its $T_{g}$.

A plausible mechanism to explain reduction of $T_{g}$ after multiple exposures to elevated temperature has not been identified. It is theorized, instead, that the autoclave used to cure the panels had a temperature gradient and that Panel 346 was placed in a cooler zone than the other panels, thereby producing a less-than-optimum cured panel with a lower $T_{g}$, tensile strength, and resin elongation than Panel 344. It may be that once the RS-14 resin was postcured to this specific crosslinked structure, future improvements in $T_{g}$ became impossible because of either impeded molecular mobility or an altered chemistry that prevented additional cyclotrimerization. This differs somewhat from epoxies whose $T_{g}$ can usually be raised (up to a point) by taking the resin to increasingly higher postcure temperatures. Further investigation is required to verify whether polycyanate resins and their composites, which for one reason or another do not reach the full postcure temperature, can be "salvaged" or recovered by exposing them to an additional cure cycle.

With the exception of Panel 346, the shear modulus of neat RS-14 resin is in the range of 150 to $160 \mathrm{ksi}$. There is a correlation between shear modulus and $T_{g}$ in this data set; the lower the $T_{g}$ of the panel, the higher its shear modulus.

\subsubsection{Tensile Properties}

Tensile testing was accomplished per ASTM D-638 (Tensile Properties of Rigid Plastics) using dogbone specimens cut from the panels. The gagelength sections of all of the specimens was polished lightly with sandpaper to reduce surface flaws and marks from the cutting operation. The modulus and elongation were measured using an extensometer clipped to the gagelength.

Excluding Panel 346, the tensile modulus of neat RS-14 resin is in the range of 410 to 430 ksi. The modulus was calculated from the initial slope of the tensile load-versus-deflection curve. As with shear modulus, there is a correlation between shear modulus and $T_{g}$ in this data set; the lower the $T_{g}$ of the panel, the higher its tensile modulus. 
The highest tensile strengths are from Panels 342 and 344 and are 11,333 psi and 11,133 psi, respectively. The cure cycle of both panels is similar in that the resin was precured at an intermediate temperature for several hours and then ramped directly to the postcure temperature. The average percent elongations of both panels is $4 \%$ although the percent coefficient of variation is high (greater than $20 \%$ ), probably reflecting the consequences of surface and internal flaws on the specimen. The highest individual percent elongation values for both panels are slightly over $5 \%$.

Panel 346, which was cured in the same process cycle as Panel 344 but received two additional postcure cycles, has an average tensile strength and percent elongation that is significantly lower (9295 psi and 2.5\%, respectively) than Panel 344. One theory is that the additional postcure cycles in air may be causing surface oxidation of the resin. The oxidized material then acts as a flaw, reducing the strength of the specimen. In theory (although not tested in practice), removing the surface-oxidized resin and testing the interior bulk resin would reveal no degradation of tensile properties caused by performing additional postcure cycles at elevated temperatures. An alternative approach would be to perform the additional postcure cycles in an inert atmosphere, such as nitrogen.

An indication of this oxidation is the color of the RS-14 resin tensile specimens and panels. Examination of Panels 342 and 344 show that the cured RS-14 resin is a milky, chocolate-brown color; Panel 346 is a darker brownish-black color. The dark color is easily removed by light sanding of the resin surface.

The data in Table 3.2.1-1 show a correlation between $\mathrm{T}_{\mathrm{g}}$ and tensile properties. In general, the higher the $T_{g}$, the higher the average tensile strength and percent elongation of the panel. This suggests that the low(er) $T_{g}$ panels are not fully cured and have not developed their maximum mechanical properties. This also supports the proposition that Panel 346 may have been cured in a slightly cooler region of the autoclave than the other panels and therefore did not fully crosslink. If so, its tensile properties would be expected to be lower.

The Statistical Analysis Program for MIL-HDBK-17 (STAT17), Revision 3.1, 4 November 1992 was used to analyze batch-to-batch variability between the sets of RS-14 resin tensile data. (STAT17 determines the statistically based mechanical properties according to procedures outlined 
in MIL-HDBK-17 on Polymer Matrix Composites.) The analysis showed significant batch-to-batch variability between the data of Panel 348 and Panel 344.

The cure cycle of Panel 348 differs from that of Panel 344 in that after the $380^{\circ} \mathrm{F}$ precure step, panel 348 was brought back to ambient temperature and removed from the mold before ramping to the postcure ternperature. Its average tensile strength is 10,214 psi with an average elongation of $3.3 \%$. Tensile specimens from Panel 348 are the same milky chocolate-brown as Panels 344 and 342 , indicating no apparent surface oxidation. The $\mathrm{T}_{\mathrm{g}}$ of Panel 348 is $512^{\circ} \mathrm{F}$ indicating that it should be fully crosslinked. These limited data suggest that interrupting the cure process by returning to ambient conditions after the precure step may be detrimental to the tensile properties of the resin.

Similarly, Panel 350 also has a significantly lower average tensile strength (9708 psi) and elongation (2.9\%). Panel 350 by-passed the precure step altogether and was ramped directly from room temperature to the positcure temperature. The overall color of Panel 350 is a slightly darker brown than Panels 342, 344 and 348, and some areas near the panel edges are distinctly darker than in the center. However, although some oxidation may have occurred during postcure, the tensile specimen gage lengths were in the lighter brown regions away from the panel edges, and the highest tensile strength recorded for this set was 10,465 psi and a $3.3 \%$ elongation.

The $487^{\circ} \mathrm{F} \mathrm{T}_{\mathrm{g}}$ of Panel 350 is somewhat lower than the optimum $510^{\circ} \mathrm{F}$ value, suggesting that this panel also did not cure properly. It is interesting to note, however, that Panel 348 was postcured in the same autoclave cycle as Panel 350 and had a measured $T_{\mathrm{g}}$ of $512^{\circ} \mathrm{F}$. Provided Panel 350 reached the full postcure temperature, the data imply that the precure portion of the cure cycle may be beneficial to achieving full cyclotrimerization of the RS-14 resin.

Panel GL-10/20/95 was fabricated by ORNL/ORCMT using a process cycle similar to what was used to make Panel 348. However, its lower $T_{g}$ and tensile properties indicate that it did not cure adequately, even though it was given a full $510^{\circ} \mathrm{F}$ postcure.

These data illustrates two points about RS-14 resin:

(1) The RS-14 resin requires the right set of process conditions (temperature, environment, and rate of reaction) to achieve optimum cure. 
(2) Less than optimum cure can result in a material with a low $\mathrm{T}_{\mathrm{g}}$ and one that has a low tensile strength and percent elongation.

The second point is significant because a reduced percent elongation at failure may compromise the strength of the wet-wound T1000G/RS-14 composite. If the RS-14 resin has only a $2-3 \%$ elongation after cure, its strain-to-failure capability may not fully accommodate the $2 \%$ elongation capability of the $\mathrm{T} 1000 \mathrm{G}$ fiber. In general, brittle or low-elongation resins yield lower fiber strength translations in composite. It is also to be expected that the reduced $T_{g}$ and less-thanoptimum crosslink structure would yield a system that is more creep-prone at elevated temperatures.

There are presently three theories to advance that may explain the RS-14 resin property variability encountered in this study. These theories revolve around meeting the proper "conditions" to fully crosslink the RS-14 resin and are as follows:

(1) Some of the panels are being cured in slightly cooler region of the autoclave and are not reaching the full $510^{\circ} \mathrm{F}$ postcure temperature.

(2) The precure step is in some way beneficial to the cure kinetics of triazine ring formation. An in-depth study of the cure chemistry and reaction kinetics of the RS14 resin would be extremely valuable in the understanding of what is significant when optimizing the resin process cycle.

(3) The environment during cure can affect the degree of cure of polycyanate resins. This third theory comes from conversations with YLA Incorporated on the formation of chemical species called carbamates that can form in polycyanate resin composites if moisture is present during the cyclotrimerization ("crosslinking") of the resin during cure. Carbamate formation is somewhat catalyzed by the presence of certain metal ions, but moisture is the chief culprit. Carbamates decompose to $\mathrm{CO}_{2}$ at elevated temperatures $\left(-400^{\circ} \mathrm{F}\right)$ creating voids and blister-like defects in composites. Their formation may also hinder the cyclotrimerization reaction to the point that a less-then-optimum crosslinked structure is achieved when the resin is taken to the postcure temperature, ultimately lowering the $T_{g}$ and tensile properties of the resin.

With respect to the question of moisture and carbamate formation, because all of the resin panels provided by YLA were fabricated in the same time period and at the same facility, it is a reasonable supposition that moisture contamination was probably no different from one panel to another. Therefore the material property differences should, in theory, not be totally the result of 
moisture contamination.

\subsubsection{Elevated Temperature Properties}

Table 3.2.1-2 summarizes the tensile properties of the RS- 14 resin at $275^{\circ} \mathrm{F}$. All four panels were cast and cured in the same autoclave cycle using a $380^{\circ} \mathrm{F}$ precure and followed by a prompt ramp to $510^{\circ} \mathrm{F}$ for postcure. Panels 346 and 347 received two additional postcure cycles to $510^{\circ} \mathrm{F}$ in air.

The best data are from Panels 344 and 345 . They show that at $275^{\circ} \mathrm{F}$, the RS-14 tensile modulus is reduced to $301 \mathrm{ksi}$ which is roughly $75 \%$ of its $410 \mathrm{ksi}$ value at room temperature. Its tensile strength is reduced to $9247 \mathrm{psi}$ from $11,133 \mathrm{psi}$ (a 17\% reduction), and its elongation at failure increases from 4 to $6 \%$.

As discussed in the preceding section, the data from Panels 346 and 347 may be biased due to surface oxidation from the additional postcure cycles in air. The tensile moduli of these panels at both room and elevated temperature are higher than their Panel 344/345 counterparts suggesting that the bulk resin may also have been embrittled. The tensile strength of Panel 347 at $275^{\circ} \mathrm{F}$ is significantly lower than both the room temperature data from Panel 346 and the elevated temperature data of Panel 345. The fact that its tensile elongation decreased at elevated temperature suggests that the material is more brittle and susceptible to surface flaws.

\subsubsection{Summary}

The combination of the data from Panels 342, 344, 348 and 350 suggests that the optimum cure cycle for RS-14 resin includes an intermediate precure step of $270^{\circ}-380^{\circ} \mathrm{F}$ followed by a prompt ramp to the postcure temperature. To develop the full set of properties, the RS-14 resin requires a

$510^{\circ} \mathrm{F}$ postcure temperature. Less than optimum cure results in a resin system that has a lower $T_{g}$, lower tensile strength, and lower strain-to-failure.

The data from Panels 346 and 347 indicate that once postcured, multiple ramps to the postcure temperature (at least in air) can degrade resin tensile properties. If feasible, RS-14 resin should be postcured in an inert atmosphere to prevent oxidation of the surface. 
Further study and research are recommended on the significance of reaction kinetics and the presence of environment (moisture) on the cure behavior and (ultimately) thermal and mechanical properties of RS-14 resin.

\section{COMPOSITE PROCESS TRIALS}

The objective of this activity was to conduct process optimization trials for T1000G/RS-14 composite as well as investigate the effect of alternate cure schedules on composite properties. This study included verifying the repeatability of a specific process and generating a set of T1000G/RS14 composite mechanical properties at elevated $\left(275^{\circ} \mathrm{F}\right)$ temperature.

\subsection{MANDREL}

The T1000G/RS-14 composite cylinders in this study were wet-wound on an internally heated steel mandrel. This mandrel was designed and constructed to provide capability to wet-wind thick hoop reinforced carbon fiber/polycyanate resin composites. A summary of the mandrel design and features is provided in this section.

The mandrel body consists of a 1.25 in. thick cylindrical shell made from 4340 steel that has been heat treated to obtain a 300-330 Brinell hardness. The cylindrical shell is supported between steel end plates. The shafts for chucking the mandrel into the winding machine are $4 \mathrm{in}$. OD $\times 5 / 8$ in. wall thickness steel tubing that are welded to the end plates.

The mandrel was fabricated with a 24 in. OD so that it could be used to wet-wind composite specimens compatible with existing ORNL/ORCMT ring tensile test fixtures and its overall length is 19 in. The mandrel surface was flash chromed to prevent rusting and protect the surface. The shell concentricity after machining met or exceeded the 0.0005 in. tolerance specified by the design.

The mandrel is internally heated with an array of eight radiant heaters that are focused on the shell ID and that are mounted at equal distances around the center assembly. The heaters are wired through a slip ring so the mandrel surface temperature can be heated and controlled while the mandrel is rotated in the winding machine. Heater output is adjusted by a variac potentiometer to provide a specific mandrel temperature. Temperature control can be maintained nominally within $+/-5^{\circ} \mathrm{F}$ of a set point during winding. 
A set of nominal 1/8 in. diameter $\times 1$ in. deep holes were drilled into both side faces of the mandrel for the insertion of thermocouple probes so that accurate temperature measurements of the mandrel shell can be made. A set of four holes was drilled into each side face of the mandrel shell just below the OD surface and spaced $90^{\circ}$ apart from one another; another set of holes was drilled into each side face near the mandrell shell ID.

As part of this study, temperature measurements were made periodically during the winding process by stopping the mandrel and inserting a thermocouple probe into the hole(s) to check the ID and OD surface temperatures at various locations on the mandrel. It is technically feasible, however, to make continuous shell temperature measurements during winding by wiring the thermocouple wire through the slip ring and to a temperature readout.

\subsection{COMPOSITE CYLINIDER FABRICATIONS}

The composite process trials were conducted by wet-winding nominal $1 / 8$ in. wall thickness hoop-wound cylinders on the internally heated steel mandrel. The fiber reinforcement was T1000G fiber from lot number 615022. Only the spools which had been sampled for tensile properties as part of the T1000G lot characterization activity (Sect. 2) were selected for winding. The resin used in all of the cylinder fabrications was RS-14 resin from the YLA reference (or batch) number FB3K702 (manufactured September 26, 1995).

Many of the wet-winding parameters used to fabricate the cylinders were developed as part of previous polycyanate resin process development at ORNL/ORCMT. The pot temperature was maintained between $175^{\circ}-180^{\circ} \mathrm{F}$ to provide a nominal resin impregnation viscosity of 0.53 poise (based on test results in Sect. 3.1). A.ll intermediate contact points between the wet-out pot and the mandrel were heated with infrared heat lamps to maintain a reduced viscosity and to keep the pulleys and contact points free of resin and fuzz buildup.

The internal heaters of the mandrel were set to maintain the mandrel surface temperature and the composite surface temperature between $170^{\circ}-180^{\circ} \mathrm{F}$ during winding of all composite process trial cylinders. The T1000G fiber was wound with $12 \mathrm{lbs}$ tension throughout the fabrications. Weighted stainless steel rollers were run over the hoop-wound composite during winding to provide further compaction of the fiber layer by squeezing out additional resin and air. Every layer (except the first 
ID layer) was compacted during winding, and an additional two compaction passes were applied after every 5-layer winding increment. During compaction, the excess resin was skimmed lightly from the surface with the lip of a hand-held polyethylene cup.

Experience with the internally heated steel mandrel showed that the continuous heating action can drive resin from the composite ID layer, resulting in "dry spots" or resin starved regions at the ID. This problem was prevented in this study by not wiping the first two layers of composite in order to leave a little extra resin at the cylinder ID. This procedure was effective, and none of the composite process trial cylinders had dry spots or resin starved IDs.

The composite OD surface resin content was controlled by not thoroughly wiping the last layer after compaction so that it would be slightly resin rich. After winding, the mandrel was rotated approximately one hour in the winding machine with the internal heaters supplying mandrel and composite surface temperatures between $180^{\circ}-190^{\circ} \mathrm{F}$. This step allowed some additional resin to bleed to the surface layer.

The mandrel was moved from the winding machine to the oven to cure the composite. In most of the process trials it was necessary to rotate the mandrel in the oven during cure until the resin had sufficiently gelled or "set up" in order to prevent sag and deformation. After cure, the mandrel shell was gradually cooled to $10^{\circ}-20^{\circ} \mathrm{F}$ with liquid nitrogen vapor to reduce the shell $\mathrm{OD}$. When there was sufficient clearance between the composite ID and the mandrel, the composite cylinder was slipped off the mandrel at one end.

\subsection{CURE/PROCESS SCHEDULES}

In theory, resin and composite mechanical and thermal properties should be insensitive to the cure schedule provided that they are held the minimum time necessary at the postcure temperature to complete the cyclotrimerization reaction. However, the limited wet-winding experience with polycyanate resins suggests that this premise should be verified. The objective of this study, therefore, was to investigate the effects of alternate cure schedules on T1000G/RS-14 composite mechanical and thermal properties. A secondary objective was to determine the optimum cure cycle for maximizing T1000G/RS-14 composite properties. 
The cure schedules selected for investigation in this study are based on experience curing RS-14 resin, experience derived from curing thick composite cylinders; and potential scenarios for fabricating thick composite hardware in production. The effect of these cure schedules on the neat RS-14 resin's properties was similarly investigated and presented in Sect. 3.2.

Below is a summary of the cylinder process trials and their cure schedules. With the exception of SR-0022 and SR-0023, all of the above were turned in the oven on the rotating cure stand until the oven temperature reached $380^{\circ} \mathrm{F}$. The purpose for this was to gel or "set up" the resin sufficiently to prevent sag and deformation in the composite as it cured.

Cylinder SR-0017

$2-3^{\circ} \mathrm{F} / \mathrm{min}$ ramp to $380^{\circ} \mathrm{F}$ and hold for $4 \mathrm{hr}$.

Return to ambient temperature $\left(5^{\circ} \mathrm{F} / \mathrm{min}\right.$ maximum cooldown rate)

$1-1.5^{\circ} \mathrm{F} / \mathrm{min}$ ramp to $510^{\circ} \mathrm{F}$ and hold for $4 \mathrm{hr}$.

Return to ambient temperature $\left(5^{\circ} \mathrm{F} / \mathrm{min}\right.$ maximum cooldown rate)

This concept of precuring and returning to room temperature prior to final cure has been used successfully to cure the inner stages of thick composites. The term stage refers to the fraction of total wall thickness that is wound and cured in one day. In these fabrications, the inner layer (or "stage") is precured at an intermediate temperature $\left(380^{\circ} \mathrm{F}\right)$ prior to winding the next increment of wall thickness. The inner stages of a thick composite are not taken to the final post cure temperature until after all of the composite has been wound.

A long, slow oven temperature ramp was used in the SR-0017 cylinder fabrication to bring the composite and mandrel from ambient conditions to the $510^{\circ} \mathrm{F}$ postcure temperature. This approach was unsatisfactory because the thick steel mandrel shell proved to be too much thermal mass to keep up with the oven temperature. To compensate, the oven was held manually at $510^{\circ} \mathrm{F}$ to ensure that the composite saw at least a $490^{\circ}-500^{\circ} \mathrm{F}$ postcure temperature for a minimum four hour period.

Based on this experience, the ramp to the postcure temperature was modified in all subsequent fabrications to include a step in which the oven temperature overshoots the postcure temperature and goes to $540^{\circ} \mathrm{F}$ for one hour. The oven temperature is then dropped in 20 minutes to $510^{\circ} \mathrm{F}$ and held for the full postcure time period. Thermocouples mounted to the steel tooling and mandrel show that 
this helps force the mandrel surface to reach the $510^{\circ} \mathrm{F}$ postcure temperature within the specified ramp time.

\section{Cylinder SR-0018}

$1-1.5^{\circ} \mathrm{F} / \mathrm{min}$ ramp to $510^{\circ} \mathrm{F}$ and hold for $4 \mathrm{hr}$.

Return to ambient temperature $\left(5^{\circ} \mathrm{F} / \mathrm{min}\right.$ maximum cool down rate)

This cure cycle eliminates the $380^{\circ} \mathrm{F}$ precure step and instead ramps the composite directly to the postcure temperature. This process shortens the time the part is in the oven and might be preferred in production.

Cylinder SR-0019 and Cylinder SR-0020

$2-3^{\circ} \mathrm{F} / \mathrm{min}$ ramp to $380^{\circ} \mathrm{F}$ and hold for $4 \mathrm{hr}$.

$1-1.5^{\circ} \mathrm{F} / \mathrm{min}$ ramp to $510^{\circ} \mathrm{F}$ and hold for $4 \mathrm{hr}$.

Return to ambient temperature $\left(5^{\circ} \mathrm{F} / \mathrm{min}\right.$ maximum cool down rate)

This cure cycle corresponds to the schedule used to cure the outer (last) stage of thick composites, which is first precured and then taken directly to the postcure step.

\section{Cylinder SR-0021}

(Same cure schedule as SR-0019)

After postcure, SR-0021 was stripped from the mandrel and cut in half into two bands. One band (referred to as SR-0021MAN) was placed back on the mandrel; the other half (SR-0021OFF) was set flat on its cut edge on the oven floor. Both SR-0021MAN and SR-0021OFF received two additional postcure cycles per the following schedule:

$1-1.5^{\circ} \mathrm{F} / \mathrm{min}$ ramp to $510^{\circ} \mathrm{F}$ and hold for $4 \mathrm{hr}$.

Return to ambient temperature $\left(5^{\circ} \mathrm{F} / \mathrm{min}\right.$ maximum cool down rate)

$1-1.5^{\circ} \mathrm{F} / \mathrm{min}$ ramp to $510^{\circ} \mathrm{F}$ and hold for $4 \mathrm{hr}$.

Return to ambient temperature $\left(5^{\circ} \mathrm{F} / \mathrm{min}\right.$ maximum cool down rate) 
The purpose of this cure schedule was to investigate the effects of additional postcure cycles to $510^{\circ} \mathrm{F}$ on cured T1000G/RS-14 composite properties. There are two reasons why this information is useful. One is that if a polycyanate-based adhesive or edge coating is selected for assembling composite hardware, it is probable that the composite would then have to be taken back to elevated temperatures to fully cure the coating or adhesive. The other reason concerns whether thick composite fabrications should be postcured after winding every stage, as opposed to just precuring at an intermediate temperature. In order for this to be a viable option, however, it must be demonstrated that multiple postcure cycles do no harm to the underlying composite.

\section{Cylinder SR-0022}

This fabrication experienced multiple equipment problems during the precure and postcure steps and was ultimately redone as Cylinder SR-0023.

Composite gelled while rotating in winding machine using internal heaters of mandrel as heat source.

(A blown fuse delayed ramping the mandrel's internal heaters and the shell temperature directly to $270^{\circ} \mathrm{F}$. The mandrel spent about two hours at $220^{\circ}-250^{\circ} \mathrm{F}$ by rotating it over the external strip heater until the fuse was replaced. The mandrel was then ramped to $270^{\circ} \mathrm{F}$ and held at that temperature for two hours.)

Mandrel moved to oven to complete postcure.

(The oven was ramped at $1-1.5^{\circ} \mathrm{F} / \mathrm{min}$ ramp but a local power failure caused it to turn off when the mandrel was only at $390^{\circ} \mathrm{F}$. The oven cooled back to $\sim 185^{\circ} \mathrm{F}$ overnight. The cure was reinitiated the next morning.)

$1-1.5^{\circ} \mathrm{F} / \mathrm{min}$ ramp to $510^{\circ} \mathrm{F}$ and hold for $4 \mathrm{hr}$.

Return to ambient temperature $\left(5^{\circ} \mathrm{F} / \mathrm{min}\right.$ maximum cool down rate)

Rather than scrapping SR-0022, this cylinder was included for sampling to determine the effect of the cure cycle interruptions on the composite properties. 
Cylinder SR-0023

Composite gelled while rotating in winding machine using internal heaters of mandrel as heat source.

$1.5-2^{\circ} \mathrm{F} / \mathrm{min}$ ramp to $270^{\circ} \mathrm{F}$ and hold for $1 \mathrm{hr}$.

Mandrel moved to oven to complete postcure

$1-1.5^{\circ} \mathrm{F} / \mathrm{min}$ ramp to $510^{\circ} \mathrm{F}$ and hold for $4 \mathrm{hr}$.

Return to ambient temperature $\left(5^{\circ} \mathrm{F} / \mathrm{min}\right.$ maximum cooldown rate)

This cure cycle has a lower precure temperature which makes it feasible to gel the composite while the mandrel is still rotating in the winding machine. It would be convenient for thick, stagecured fabrications because each stage could be gelled without having to move the mandrel back and forth between the winding machine and oven.

This cure cycle processed very well with the only exception being that the RS-14 resin emits a large amount of volatiles when taken above $250^{\circ} \mathrm{F}$. Volatiles are emitted continuously up until the point that the resin hardens. At present, the facilities do not have adequate ventilation to continue gelling the T1000G/RS-14 composite in the winding machine and out in the open laboratory area on a regular basis.

\subsection{COMPOSITE EVALUATION AND TESTING}

The composite cylinders were cut into specimens and tested for composition, hoop tensile strength and modulus, interlaminar shear strength and transverse flexural strength. The data are summarized in Table 4.4-1. The test methods and results are discussed in the following sections.

\subsubsection{Composition}

Composition is calculated from the measured density of the composite (obtained via a water displacement test method) and weight-percent fiber and resin contents (determined from digestion of the composite in nitric acid). The volume percent fiber, resin, and void contents are then calculated using this data, the measured neat RS-14 resin density, and the vendor-supplied T1000G fiber density. 
Table 4.4-1. Composite process trial results.

\begin{tabular}{|c|c|c|c|c|c|c|c|c|}
\hline Cylinder Number & SR-0017 & SR-0018 & SR-0019 & SR-0020 & SR-0021MAN & SR-0021OFF & SR-0022 & SR-0023 \\
\hline \multicolumn{9}{|l|}{ Ring Tensile } \\
\hline \multirow[t]{2}{*}{ Strength (ksi) } & 606.7 & 608.3 & 631.3 & NA & 567.3 & 365.2 & 588.2 & 650.6 \\
\hline & (5.1) & (3.8) & (3.9) & & (5.4) & (18.8) & (2.8) & (2.2) \\
\hline \multirow[t]{2}{*}{ Modulus (Msi) } & 32.7 & 32.2 & 32.7 & NA & 32.4 & 32.2 & 32.7 & 32.7 \\
\hline & (3.0) & $(1.2)$ & $(1.5)$ & & $(0.9)$ & (3.6) & (1.6) & $(0.9)$ \\
\hline \multirow[t]{2}{*}{ SBs Strength (psi) } & 9,271 & $\overline{\mathbf{9}}, \overline{2} \mathbf{6} \overline{0}$ & 9,453 & NA & 9,744 & 8,402 & 10,857 & 8,856 \\
\hline & $(3.7)$ & $(6.5)$ & $(6.6)$ & & (5.5) & (4.9) & $(5.0)$ & (4.4) \\
\hline \multicolumn{9}{|c|}{ Transverse Flex. Strength } \\
\hline \multirow[t]{2}{*}{ Concave Up (psi) } & 10,939 & 12,084 & 14,077 & 14,250 & 12,600 & 11,016 & 12,868 & 11,079 \\
\hline & $(15.8)$ & $(4.2)$ & $(8.4)$ & $(4.8)$ & (7.5) & $(17.4)$ & (2.9) & $(10.8)$ \\
\hline \multirow[t]{2}{*}{ Concave Down (psi) } & 6,864 & 7,922 & 7,281 & NA & 3,703 & 6,765 & 7,668 & 7,161 \\
\hline & (5.2) & $(4.0)$ & (11.1) & & (7.1) & $(8.8)$ & (7.9) & $(10.2)$ \\
\hline \multicolumn{9}{|l|}{ Composition } \\
\hline Density (gm/cm3) & 1.6631 & 1.6664 & 1.6607 & 1.6647 & 1.6667 & 1.6667 & 1.6669 & 1.6667 \\
\hline Volume \% Fiber & 78.6 & 78.9 & 78.4 & 78.7 & 79.6 & 79.6 & 79.2 & 79.3 \\
\hline Volume \% Resin & 21.3 & 21.2 & 21.5 & 21.3 & 20.1 & 20.1 & 20.8 & 20.6 \\
\hline Volume \% Voids & 0.1 & $(-0.1)$ & 0.1 & 0.0 & 0.3 & 0.3 & 0 & 0.1 \\
\hline
\end{tabular}

( ) Number in parentheses is percent coefficient of variation.

NA - Not available

Number of specimens: ring tensile (8-11); SBS strength (17-18); transverse flex. strength (10-11 each concave up and concave down). 
The data in Table 4.4-1 show that all composite process trial cylinders have approximately the same compositions. This is to be expected because they were all wet-wound using the same process parameters. It also shows that the compositions can be reproduced successfully provided these parameters are controlled.

The composite densities are on the order of $1.66 \mathrm{~g} / \mathrm{cm}^{3}$, and the fiber contents range between 78.4 to 79.6 volume percent. The difference between the highest and lowest fiber fraction is only 1.2 volume percent for seven cylinder fabrications. These fiber contents are also comparable to the levels obtained in T1000G/RS-14 composite in previous process trials ${ }^{1}$. The volume percent void levels are low and less than 0.5 volume percent. These, too, are comparable to previous results.

\subsubsection{Ring Tensile}

The ring tensile test uses a nominal $1 / 4$ in. wide $\times 1 / 8$ in. thick ring specimen that is loaded in hoop tension by a split-D fixture mounted in an oil-driven Tinius Olsen test machine. The specimen geometry and test method are similar to what is specified in the ASTM standard test method D2290, but the $24 \mathrm{in}$. ring diameter is larger in this application.

The composite ring is placed on the outer diameters of the split-Ds, and a tensile load is applied by pulling the Ds apart with a clevis/pin type loading mechanism. The split-D fixtures are solid steel plates that are nominally 1 in. thick. Friction between the composite ring and the Ds during loading is reduced by lining the inner diameter of the composite ring with Teflon tape prior to installation. The specimens are loaded to failure and the break load is recorded. The break loads, in conjunction with the cross-sectional area, are used to calculate the apparent hoop tensile strength for the composite material.

An extensometer is used to measure deflection at the opening of the Ds. The load-deflection curve is plotted to approximately 6000 microstrain, and then the extensometer is removed to prevent it from getting damaged when the ring fails. The measured load and deflection are then used to calculate the composite hoop (fiber direction) modulus in the initial 1000-6000 microstrain range. 
The ring or hoop tensile modulus for all of the process trial cylinders ranges between 32.3 to $32.7 \mathrm{Msi}$. There is very good agreement in the hoop modulus values of the cylinders. This is to be expected based on the fact that the hoop tensile modulus is dominated by the modulus of the carbon fiber and that the cylinders were fabricated with virtually the same fiber compositions.

The ring tensile strength data showed higher variability than expected which appears to be partly due to the differences in the process cycles. The best data were obtained from Cylinder SR-0023 which was gelled (precured) at $270^{\circ} \mathrm{F}$ in the winding machine and then ramped promptly to the $510^{\circ} \mathrm{F}$ postcure temperature in the oven. The average tensile strength is $650.6 \mathrm{ksi}$ with a relatively small $2.2 \%$ coefficient of variation. The highest individual ring tensile strength in this set was $681 \mathrm{ksi}$ which is one of the higher individual ring specimen strengths measured in this study.

Table 4.4.2-1 shows the calculated T1000G fiber strength translations for each of the cylinders. The fiber strength translation is obtained by dividing the measured ring tensile strength by the product of the fiber strength and the fiber fraction in the composite, i.e.,

$$
\text { fiber strength translation }=\frac{\text { ring tensile strength } \times 100}{\text { T1000G strength } \times V_{f}}
$$

where $V_{f}$ is the volume percent fiber fraction of the composite

It is therefore a measure of the efficiency of the carbon fiber in transferring its tensile strength to the composite. The fiber strength translations in Table 4.4.2-1 were calculated using two methods. In one method, the T1000G fiber strength was obtained by averaging the start and end tensile strengths of the all of the spools used to fabricate the cylinders (see Tables 2-1 and 2-2); in the other method the strength translations were calculated using the $954 \mathrm{ksi}$ lot tensile strength average obtained from the T1000G lot characterization study.

Based on these methods, the fiber strength translations for Cylinder SR-0023 is $85-86 \%$ and is also higher than the strength translations obtained for the other cylinders.

The average ring tensile strength of SR-0022 is significantly lower than the data of SR-0023. SR-0022 in theory went through a similar precure and postcure schedule but, as described in the preceding section, was plagued by equipment problems that caused delays in the process. The precure step on the mandrel was delayed two hours, and an interruption in the oven power supply 
Table 4.4.2-1. T1000G fiber strength translation.

\begin{tabular}{|c|c|c|c|c|c|c|c|c|}
\hline Cylinder Number & SR-0017 & SR-0018 & SR-0019 & SR-0020 & SR-0021MAN & SR-0021OFF & SR-0022 & SR-0023 \\
\hline Ring Tensile Strength (ksi) & $\begin{array}{l}606.7 \\
(5.1)\end{array}$ & $\begin{array}{c}608.3 \\
(3.8)\end{array}$ & $\begin{array}{c}631.3 \\
(3.9)\end{array}$ & NA & $\begin{array}{l}567.3 \\
(5.4)\end{array}$ & $\begin{array}{l}365.2 \\
(18.8)\end{array}$ & $\begin{array}{c}588.2 \\
(2.8)\end{array}$ & $\begin{array}{c}650.6 \\
(2.2)\end{array}$ \\
\hline Volume \% Fiber & 78.6 & 78.9 & 78.4 & 78.7 & 79.6 & 79.6 & 79.2 & 79.3 \\
\hline Spool Numbers & 9,10 & 10,11 & $11,12,13$ & $13,14,15$ & $15,16,17$ & $15,16,17$ & 17,18 & 19,20 \\
\hline \multicolumn{9}{|c|}{ T1000G Fiber Strength (ksi) } \\
\hline $\begin{array}{l}\text { Start of Spool } \\
\text { End of Spool } \\
\text { Spool Average }\end{array}$ & $\begin{array}{c}959,890 \\
971,927 \\
937\end{array}$ & $\begin{array}{c}890,948 \\
927,965 \\
932\end{array}$ & $\begin{array}{c}948,970,939 \\
965,972,984 \\
963\end{array}$ & $\begin{array}{c}939,927,928 \\
984,935,962 \\
945\end{array}$ & $\begin{array}{c}928,951,978 \\
962,955,945 \\
953\end{array}$ & $\begin{array}{c}928,951,978 \\
962,955,945 \\
953\end{array}$ & $\begin{array}{c}978,994 \\
945,964 \\
970\end{array}$ & $\begin{array}{c}985,938 \\
970,967 \\
965\end{array}$ \\
\hline \multicolumn{9}{|c|}{ Fiber Strength Translation } \\
\hline $\begin{array}{l}\text { Spool Average } \\
\text { Lot No. } 615022 \text { Average * }\end{array}$ & $\begin{array}{l}82.4 \\
80.9\end{array}$ & $\begin{array}{l}82.7 \\
80.8\end{array}$ & $\begin{array}{r}83.6 \\
84.4 \\
\end{array}$ & $\begin{array}{l}\text { NA } \\
\text { NA } \\
\end{array}$ & $\begin{array}{l}74.8 \\
74.7 \\
\end{array}$ & $\begin{array}{l}48.1 \\
48.1\end{array}$ & $\begin{array}{l}76.6 \\
77.8 \\
\end{array}$ & $\begin{array}{l}85.0 \\
86.0\end{array}$ \\
\hline
\end{tabular}

( ) Number in parentheses is percent coefficient of variation

NA - Not available

- 954 ksi 
when the part was only at $390^{\circ} \mathrm{F}$ meant that the ramp to postcure had to be re-initiated the following day. The fiber strength translation for SR-0022 is roughly only $77 \%$. These data indicate that the cured properties of the T1000G/RS-14 composite may be sensitive to the cure schedule.

SR-0019 was cured using a similar process cycle to SR-0023 except that the precure temperature was $380^{\circ} \mathrm{F}$ instead of $270^{\circ} \mathrm{F}$. The average ring tensile strength of SR-0019 is $631 \mathrm{ksi}$ and the fiber strength translation is roughly $84 \%$. The Statistical Analysis Program for MIL-HDBK17 (STAT17), Revision 3.1, 4 November 1992, was used to analyze batch-to-batch variability and found no statistical difference in the data of SR-0019 and SR-0023.

SR-0017 was processed differently from SR-0023 and SR-0019 in that after the precure step, the mandrel was returned to ambient conditions before ramping back up to the $510^{\circ} \mathrm{F}$ postcure temperature. The average ring tensile strength is lower and is $607 \mathrm{ksi}$; the fiber strength translation is also lower and is approximately $81-82 \%$. STAT17 found no batch-to-batch variability between the tensile data of SR-0017 and SR-0019. However, when the SR-0017 data is compared with the data of SR-0023 or combined with the data sets from SR-0023 and SR-0019, there is significant batch-to-batch variability.

SR-0018 by-passed the precure step altogether and was ramped directly to the postcure temperature after being placed in the oven. Its average ring tensile strength is $608 \mathrm{ksi}$ and the fiber strength translations are 81-83\%. These data are comparable to the data of SR-0017. As before, STAT17 found no batch-to-batch variability between the tensile data of SR-0018 and SR-0019. However, when the SR-0018 data are compared with the data of SR-0023 or combined with the data sets from SR-0023 and SR-0019, there is significant batch-to-batch variability.

The data of Cylinders SR-0021MAN and SR-0021OFF show that additional postcure cycles are detrimental to the ring tensile strength of T1000G/RS-14 composite. The SR-0021 cylinder was cured with the same schedule as the SR-0019 cylinder and theoretically would have the same 631 ksi ring tensile strength had it not been postcured two additional times. The tensile strength reduction is either caused by oxidation of the composite OD surface layer and/or bulk changes to the composite material properties. SR-0021OFF, which was postcured free-standing and unsupported, underwent the greatest degradation, probably as a result of the creation of microscopic flaws in the composite from the thermal cycling. SR-0021MAN was postcured supported at the ID by the 
mandrel but still suffered a $10 \%$ reduction in tensile strength based on the $631 \mathrm{ksi}$ ring tensile data of SR-0019.

\subsubsection{Ring Width and Tensile Strength}

A set of $1 / 8$ in. wide ring specimens was cut from the SR-0022 cylinder and submitted with the 1/4 in. wide rings for testing. The data are presented in Table 4.4.3-1 and show that the 1/4 in. wide set of rings yielded an average tensile strength that is approximately $35 \mathrm{ksi}$ higher than tensile strength of the $1 / 8$ in. wide rings. The Statistical Analysis Program for MIL-HDBK-17 (STAT17) was used to analyze the two sets of ring strength data and found that the batch-to-batch variability was significant.

The data suggest that strength measurements are influenced by the number of surface flaws, such as those produced from machining the specimens. Materials that are brittle are more susceptible to surface flaws than tougher, high-elongation materials and the surface flaw-to-volume ratio is higher for the thinner rings. They would therefore be expected to have a lower strength.

\subsubsection{Interlaminar Shear}

The interlaminar shear test uses a curved short beam shear specimen geometry based on the ASTM D2344 standard test method with the fiber direction being parallel to the beam axis. The specimens are machined from a partial circumferential length of $1 / 4 \mathrm{in.} \mathrm{wide} \mathrm{x} 1 / 8 \mathrm{in}$. thick ring specimen, similar to what is used for the ring tensile test. The circumferential length of the short beam shear specimen is $3 / 4$ in. Testing is accomplished with a nominal 4:1 span-to-depth ratio. The specimens are loaded to failure, and the break load is recorded. The apparent interlaminar shear strength is calculated from the break load and specimen geometry.

The data in Table 4.4-1 show that the T1000G/RS-14 composite interlaminar shear strength is not affected by the cure schedule used to cure the composite. The Statistical Analysis Program for MIL-HDBK-17 (STAT17) was used to analyze batch-to-batch variability and found no statistical difference in the data of SR-0019 (precured, then ramped promptly to postcure), SR-0017 (returned 
Table 4.4.3-1. Ring width versus tensile properties.

\begin{tabular}{|ccc|}
\hline Composite Cylinder & SR-0022 & SR-0022 \\
\hline \hline Ring Width & $1 / 4$-inch & $1 / 8$-inch \\
No. of Specimens & 8 & 5 \\
& & \\
Strength (ksi) & 588.2 & 552.9 \\
& $(2.7)$ & $(2.5)$ \\
Modulus (Msi) & 32.7 & 32.9 \\
& $(1.6)$ & $(1.5)$ \\
\hline \hline
\end{tabular}

( ) Number in parentheses is percent coefficient of variation 
to room temperature after precure and then ramped to postcure), and SR-0018 (ramped directly to postcure without a precure step). These data are also comparable to previously reported T1000G/RS14 interlaminar shear strengths.'

The interlaminar shear strength of SR-0021MAN (cured the same as SR-0019 and then given two additional postcure cycles while supported on mandrel) was not degraded $(9,744$ psi) even though its ring tensile strength had deteriorated. This may be explained by the fact that interiaminar shear failure occurs in the midplane of the cylinder wall thickness which presumably was not exposed to the atmosphere during the additional postcure cycles. SR-0021OFF received the same two additional postcure cycles but was unsupported (freestanding) during heat treatment. Its interlaminar shear strength is significantly lower $(8,402 \mathrm{psi})$ which is believed to be a result of microscopic cracks and flaws produced from deformations in the composite during the thermal cycles.

The interlaminar shear strength of the SR-0023 cylinder, which had the highest average ring tensile strength of the group (650 ksi), is statistically lower $(8,856 \mathrm{psi})$ than SR-0019, SR-0018 and $\mathrm{SR}-0017$. Conversely, the interlaminar shear strength of SR-0022, which had one of the lower ring tensile strengths (588 ksi), is statistically higher $(10,857 \mathrm{psi})$ than the other cylinders. A possible explanation may be found from the neat resin panel data which showed that less-then-optimally cured RS-14 resin had a lower $\mathrm{T}_{\mathrm{g}}$ and elongation at failure but also tended to have a higher tensile and shear modulus. The higher resin moduli during the shear test may offset the low strain-to-failure of the resin and produce an interlaminar shear strength that is as good or higher than a lower modulus resin with a higher strain-to-failure.

The lack of correlation between process cycle and interlaminar shear strength may also be due to the strength of the carbon fiber-resin interface. If failure is occurring between the carbon fiber and the fiber sizing, then the condition of the resin between fibers will not have much impact on the measured strength.

\subsubsection{Transverse Flexure}

The transverse flexure test uses a $1 / 4$ in. wide $x 4$ in. long beam specimen that is loaded in 4-point bending in the rz-plane. The specimens are machined from a partial circumferential length 
of $\mathrm{a} 4 \mathrm{in}$. wide $\mathrm{x} 1 / 8 \mathrm{in}$. thick composite band. The axis of the beam (z-axis) is parallel to the axis of the ring geometry and transverse to the direction of the hoop fibers in the composite cylinder.

The tests are conducted both with the concave surface (or ID) of the ring radius of curvature being on the compression side of the beam ("concave up") and on the tension side of the beam ("concave down"). All of the tests used the 4-point loading configuration with a support length to depth $(\mathrm{L} / \mathrm{d})$ ratio of 24 , where the beam depth corresponds to the composite ring thickness. The distance between support points was 3 in., and the distance between loading points was 2 in. The overall beam length is 4 in. and the width is $1 / 4$ in. The specimens are tested to failure and the break load is recorded. The break load is used to calculate the composite transverse flexural strength in accordance with ASTM D790 standard test method.

The "concave up" test configuration places the portion of the beam corresponding to the cylinder OD in tension. It is sensitive to the outermost, OD layers of the composite and the surface resin layer thickness. The "concave down" test configuration places the cylinder ID in tension and is sensitive to the innermost, ID layers of the composite. Because the ID composite layers tend to be more compacted, with a higher fiber content, and have a minimal surface resin layer, the transverse tensile strength of these layers is expected to be lower than for the layers at the OD. For this reason, the concave up transverse flexural strengths are nearly twice the value of the concave down strengths.

The Statistical Analysis Program for MIL-HDBK-17 (STAT17) was used to analyze batch-tobatch variability and found significant batch-to-batch variability for the concave up data sets. The highest concave up transverse flexural strengths are from SR-0019 and SR-0020 (14, 077 psi and $14,250 \mathrm{psi}$, respectively) which were both precured at $380^{\circ} \mathrm{F}$ and then ramped promptly to $510^{\circ} \mathrm{F}$ for the postcure. The lowest concave up transverse flexural strength is from SR-0017 (10,939 psi) which was precured, returned to ambient temperature and then ramped to the postcure temperature. The concave up transverse flexural strength of SR-0018 (ramped directly to the postcure temperature without a precure step) is $12,084 \mathrm{psi}$ and is intermediate between the two. However, because the concave up transverse flexural strength test is sensitive to the OD surface finish and resin content, these strength variations may be typical for a hoop-wound composite. 
The SR-0023 cylinder (precured at $270^{\circ} \mathrm{F}$ in the winding machine and then ramped promptly to postcure in the oven) has only a 11,079 psi concave up transverse flexural strength even though its ring tensile strength data are statistically similar to the SR-0019 fabrication and are the highest for all of the cylinders. Its interlaminar shear strength was also lower than that of the other cylinders. The reason for this is unknown.

SR-0021MAN and SR-0021OFF were cured using the same schedule as SR-0019 and SR-0020 with the exception of receiving the two additional postcure cycles. In theory, their concave up transverse flexural strength should also be on the order of 14,000 psi. Although the values are lower $(12,600 \mathrm{psi}$ and 11,016 psi, respectively), they are not significantly lower than the values of some of the other cylinders. This suggests that although the composite OD was postcured in air, and probably experienced resin oxidation damage comparable to that encountered with the neat resin panels, the concave up transverse flexural strength is still reasonably good.

The SR-0021MAN concave down transverse flexural strength is, however, significantly degraded from the additional postcure cycles. SR-0021MAN was postcured while supported on the generic ring mandrel. Its concave down transverse flexural strength is almost half that of the other cylinders ( $3703 \mathrm{psi}$ ) and is even less than the corresponding value for SR-0021OFF (6,765 psi), which also was postcured in air but was free-standing (unsupported). It is believed that the thermal cycling on the steel mandrel produced damage and flaws at the composite ID which resulted in the lower transverse flexural strength.

With the exception of SR-0021MAN and SR-0021OFF, no correlation could be made between the concave down transverse flexural strengths and the cure schedules used to fabricate the composite. All of the values fall in the range of $6800-7900$ psi.

\subsection{REPRODUCIBILITY TRIALS}

The objective of this activity was to determine how well a set of composite mechanical and physical properties can be the reproduced when a specific cure schedule and set of processing procedures are used to fabricate the composite. A reproducible manufacturing process is a process that is well understood and in control. A reproducible manufacturing process is essential in order to be able to reliably and efficiently produce composite hardware with the requisite set of properties that is demanded 
by certain applications.

\subsubsection{Cure/Process Schedules}

Two cure cycles were selected for evaluating the reproducibility of the process. These correspond to the process cycles used to cure SR-0019 and SR-0017. The SR-0019 process cycle yielded one of the best sets of mechanical properties; the SR-0017 process cycle may be necessary in the fabrication of thick (stage-cured) composite hardware.

Two composite cylinders were fabricated and cured as part of this study. A summary of the cylinders and cure schedules is provided below:

Cylinder SR-0027 (same as Cylinder SR-0019)

$2-3^{\circ} \mathrm{F} / \mathrm{min}$ ramp to $380^{\circ} \mathrm{F}$ and hold for $4 \mathrm{hr}$.

$1-1.5^{\circ} \mathrm{F} / \mathrm{min}$ ramp to $510^{\circ} \mathrm{F}$ and hold for $4 \mathrm{hr}$.

Return to ambient temperature $\left(5^{\circ} \mathrm{F} / \mathrm{min}\right.$ maximum cooldown rate)

Cylinder SR-0028 (same as Cylinder SR-0017)

$2-3^{\circ} \mathrm{F} / \mathrm{min}$ ramp to $380^{\circ} \mathrm{F}$ and hold for $4 \mathrm{hr}$.

Return to ambient temperature $\left(5^{\circ} \mathrm{F} / \mathrm{min}\right.$ maximum cooldown rate)

$1-1.5^{\circ} \mathrm{F} / \mathrm{min}$ ramp to $510^{\circ} \mathrm{F}$ and hold for $4 \mathrm{hr}$.

Return to ambient temperature $\left(5^{\circ} \mathrm{F} / \mathrm{min}\right.$ maximum cooldown rate)

The above cylinders were tested for ring tensile strength and modulus, interlaminar shear strength, transverse flexural strength, and composition.

In addition, a 4 in. wide band was cut from the SR-0027 fabrication and placed back onto the mandrel. The composite then received two additional postcure cycles per the following schedule:

$1-1.5^{\circ} \mathrm{F} / \mathrm{min}$ ramp to $510^{\circ} \mathrm{F}$ and hold for $4 \mathrm{hr}$.

Return to ambient temperature $\left(5^{\circ} \mathrm{F} / \mathrm{min}\right.$ maximum cooldown rate)

$1-1.5^{\circ} \mathrm{F} / \mathrm{min}$ ramp to $510^{\circ} \mathrm{F}$ and hold for $4 \mathrm{hr}$.

Return to ambient temperature $\left(5^{\circ} \mathrm{F} / \mathrm{min}\right.$ maximum cooldown rate)

The band was relabeled SR-0027MAN and it was tested for transverse flexural properties. The objective was to verify the low concave transverse flexural strength values of the SR-0021MAN process trial. 


\subsubsection{Test Results}

Table 4.5.2-1 summarizes the test results from Cylinders SR-0027, SR-0028 and SR-0027MAN. The data from their identically processed counterparts is listed beside them for comparison. The data show that there is good agreement between the density, composition, and ring tensile modulus data for all of the fabrications. The interlaminar shear strength data also show good agreement for all of the fabrications including one of the composites that received two additional postcure cycles on the mandrels (SR-0021MAN).

The Statistical Analysis Program for MIL-HDBK-17 (STAT 17) was used to analyze batch-to-batch variability and found no statistical difference in the ring tensile strength data of SR-0017, SR-0028, SR-0019 and SR-0027. The average ring tensile strength for SR-0028 was slightly higher ( $629.8 \mathrm{ksi}$ ) than for SR-0017 (606.7 ksi), but the difference is statistically insignificant. Both cylinders were precured at $380^{\circ} \mathrm{F}$, returned to ambient conditions, and then ramped to $510^{\circ} \mathrm{F}$ for postcure. The average ring tensile strength for SR-0027 is significantly lower (592.6 ksi) than for SR-0019 (631.3 ksi). Both cylinders were precured at $380^{\circ} \mathrm{F}$ followed by a prompt ramp to $510^{\circ} \mathrm{F}$ for postcure. The reason for SR-0027 having a lower strength is unknown. The SR-0027 ring tensile data does have a high percent coefficient of variation (7.2\%) which suggests that other factors, such as possible machining flaws, may be degrading the composite strength.

Table 4.5.2-2 shows the calculated T1000G fiber strength translations for each of the cylinders. The fiber strength translations were calculated with the average of the available start and end tensile strengths of all of the spools used to fabricate the cylinders and also with the $954 \mathrm{ksi}$ lot tensile strength average obtained from the T1000G lot characterization effort (Sect. 2). Based on these methods, the fiber strength translations for Cylinders SR-0017 and SR-0028 are comparable and on the order of $81-83 \%$. The fiber strength translation for the SR-0019 cylinder is marginally higher (84\%). The SR-0027 cylinder had a significantly lower strength translation (77-78\%) indicating that the full utilization of the T1000G fiber strength was not achieved in this fabrication.

The highest individual ring tensile strength measured to-date by ORNL/ORCMT for a hoop-wound carbon composite ring was obtained from the SR-0028 cylinder and was $696.5 \mathrm{ksi}$. This data suggests that if the fiber strength translations can be improved slightly that a $700 \mathrm{ksi}$ composite hoop strength 
Table 4.5.2-1. Composite process reproducibility results.

\begin{tabular}{|c|c|c|c|c|c|c|c|}
\hline \multirow[b]{2}{*}{ Cylinder Number } & \multicolumn{2}{|c|}{ Process A } & \multicolumn{3}{|c|}{ Process B } & \multicolumn{2}{|c|}{ Process C } \\
\hline & SR-0017 & SR-0028 & SR-0019 & SR-0020 & SR-0027 & SR-0021MAN & SR-0027MAN \\
\hline $\begin{array}{l}\text { Ring Tensile } \\
\text { Strength (ksi) }\end{array}$ & $\begin{array}{c}606.7 \\
(5.1)\end{array}$ & $\begin{array}{c}629.8 \\
(5.5)\end{array}$ & $\begin{array}{c}631.3 \\
(3.9)\end{array}$ & NA & $\begin{array}{c}592.6 \\
(7.2)\end{array}$ & $\begin{array}{l}567.3 \\
(5.4)\end{array}$ & NA \\
\hline Modulus (Msi) & $\begin{array}{l}32.7 \\
(3.0)\end{array}$ & $\begin{array}{l}33.1 \\
(1.2)\end{array}$ & $\begin{array}{l}32.7 \\
(1.5)\end{array}$ & $\hat{N A A}$ & $\begin{array}{l}32.7 \\
(1.0)\end{array}$ & $\begin{array}{l}32.4 \\
(0.9)\end{array}$ & NA \\
\hline SBS Strength (psi) & $\begin{array}{c}9,271 \\
(3.7)\end{array}$ & $\begin{array}{l}9,586 \\
(3.5)\end{array}$ & $\begin{array}{l}\overline{9}, \overline{453} \\
(6.6)\end{array}$ & NA & $\begin{array}{c}10,017 \\
(7.7)\end{array}$ & $\begin{array}{c}9,744 \\
(5.5)\end{array}$ & NA \\
\hline $\begin{array}{l}\text { Transverse Flex. Strength } \\
\text { Concave Up (psi) }\end{array}$ & $\begin{array}{c}10,939 \\
(15.8)\end{array}$ & $\begin{array}{c}12,109 \\
(6.0)\end{array}$ & $\begin{array}{c}14,077 \\
(8.4)\end{array}$ & $\begin{array}{c}14,250 \\
(4.8)\end{array}$ & $\begin{array}{c}12,330 \\
(7.8)\end{array}$ & $\begin{array}{c}12,600 \\
(7.5)\end{array}$ & $\begin{array}{c}12,618 \\
(10.3)\end{array}$ \\
\hline Concave Down (psi) & $\begin{array}{c}6,864 \\
(5.2) \\
\end{array}$ & $\begin{array}{c}7,677 \\
(9.8) \\
\end{array}$ & $\begin{array}{l}7,281 \\
(11.1) \\
\end{array}$ & NA & $\begin{array}{c}8,003 \\
(6.0) \\
\end{array}$ & $\begin{array}{c}3,703 \\
(7.1) \\
\end{array}$ & $\begin{array}{l}7,176 \\
(15.0) \\
\end{array}$ \\
\hline $\begin{array}{l}\text { Composition } \\
\text { Density }(\mathrm{gm} / \mathrm{cm} 3)\end{array}$ & 1.6631 & 1.6650 & 1.6607 & 1.6647 & 1.6648 & 1.6667 & 1.6648 \\
\hline $\begin{array}{l}\text { Volume \% Fiber } \\
\text { Volume \% Resin } \\
\text { Volume \% Voids }\end{array}$ & $\begin{array}{l}78.6 \\
21.3 \\
0.1 \\
\end{array}$ & $\begin{array}{c}79.2 \\
20.5 \\
0.3 \\
\end{array}$ & $\begin{array}{l}78.4 \\
21.5 \\
0.1 \\
\end{array}$ & $\begin{array}{c}78.7 \\
21.3 \\
0 \\
\end{array}$ & $\begin{array}{c}79.3 \\
20.4 \\
0.3 \\
\end{array}$ & $\begin{array}{c}79.6 \\
20.1 \\
0.3 \\
\end{array}$ & $\begin{array}{c}79.3 \\
20.4 \\
0.3 \\
\end{array}$ \\
\hline
\end{tabular}

( ) Number in parentheses is percent coefficient of variation.

NA - Not available

Number of specimens: ring tensile (8-11); SBS strength (17-18); transverse flex. strength (10-11 each concave up and concave down)

Process A: $380^{\circ} \mathrm{F}$ precure; return to ambient temperature; ramp to $510^{\circ} \mathrm{F}$ postcure.

Process B: $380^{\circ} \mathrm{F}$ precure followed by ramp to $510^{\circ} \mathrm{F}$ postcure.

Process C: Same as B plus two additional $510^{\circ} \mathrm{F}$ postcure cycles on mandrel. 
Table 4.5.2-2. Reproducibility trial $\mathrm{T} 1000 \mathrm{G}$ fiber strength translations.

\begin{tabular}{|lcccc|}
\hline Cylinder Number & SR-0017 & SR-0028 & SR-0019 & SR-0027 \\
\hline \hline Ring Tensile Strength (ksi) & 606.7 & 629.8 & 631.3 & 592.6 \\
& $(5.1)$ & $(5.5)$ & $(3.9)$ & $(7.2)$ \\
Volume \% Fiber & 78.6 & 79.2 & 78.4 & 79.3 \\
& & & & \\
Spool Numbers & 9,10 & 52,53 & $11,12,13$ & 51,50 \\
& & & & \\
Start of Spool & T1000G Fiber Strength (ksi) & & \\
End of Spool & 959,890 & 944,995 & $948,970,939$ & 957,969 \\
Spool Average & 971,927 & NA & $965,972,984$ & NA \\
& 937 & 970 & 963 & 963 \\
& \multicolumn{5}{c}{} & & \\
Spool Average & Fiber Strength Translation & & \\
Lot No. 615022 Average * & 82.4 & 82.0 & 83.6 & 77.6 \\
\hline \hline
\end{tabular}

( ) Number in parentheses is percent coefficient of variation NA - Not available

- 954 ksi

SR-0017/SR-0028: $380^{\circ} \mathrm{F}$ precure; return to ambient temperature; ramp to 510 ${ }^{\circ} \mathrm{F}$ postcure. SR-0019/SR-0027: $380^{\circ} \mathrm{F}$ precure followed by ramp to $510^{\circ} \mathrm{F}$ postcure. 
is achievable in the foreseeable future. The data also indicates that polycyanate resins have a good potential as matrix materials for high strength composite applications.

The concave up and down transverse flexural strengths for the SR-0028 and SR-0027 cylinders show good agreement between each other. The SR-0027 concave up transverse flexural strength is slightly lower (12,330 psi) than for the SR-0019 and SR-0020 cylinders (14,077 psi and 14,250 psi, respectively). The SR-0028 concave up transverse flexural strength is slightly higher $(12,109 \mathrm{psi})$ than for SR-0017 (10,939 psi). However, because the concave up transverse flexural strength is sensitive to the OD surface finish and resin content, these strength variations may not be significant and may reflect normal variations in hoop-wound composite.

The SR-0027MAN cylinder (which was taken from the SR-0027 fabrication and given two additional postcure cycles on the mandrel) had an average concave up transverse flexural strength of $12,618 \mathrm{psi}$. This strength was not statistically different from the SR-0027 cylinder, which did not receive the additional postcure cycles $(12,330 \mathrm{psi})$ or the identically processed SR-0021MAN cylinder $(12,600 \mathrm{psi})$. These data suggest that two additional postcure cycles to $510^{\circ} \mathrm{F}$ in air do not necessarily degrade the composite OD layer.

The concave down transverse flexural strength for SR-0027MAN $(7,176 \mathrm{psi})$ is $10 \%$ less than for SR-0027 ( 8,003 psi), but this difference is not statistically significant. It is, however, almost twice the concave down transverse flexural of the SR-0021MAN (3,703 psi). The factors that caused degradation of the SR-0021MAN concave down transverse flexural strength are suspected to be related to thermal cycling on the mandrel. However, these factors were not replicated during the processing of SR-0027MAN. Further experimental work is recommended to confirm the effects of multiple postcure cycles on T1000G/RS-14 composite.

\subsection{ELEVATED TEMPERATURE DATA}

This activity was performed to provide material test properties for T1000G/RS-14 composite at elevated temperature. 


\subsubsection{Mechanical Properties}

Additional ring tensile, interlaminar shear, and transverse flexure specimens were machined from the SR-0027 and SR-0028 composite cylinders and tested at $275^{\circ} \mathrm{F}$. The data were compared to comparable ambient temperature data measured from the cylinders as part of the reproducibility study. The difference between ambient and $275^{\circ} \mathrm{F}$ properties were determined.

Table 4.6.1-1 shows the ambient and $275^{\circ} \mathrm{F}$ test data for both composite cylinders. The data show an approximate reduction in ring tensile strength of $20 \%$ for both cylinders. The short beam shear strength reduction is on the order of $15-18 \%$. With the exception of the concave up transverse flexural strength for the SR-0028 cylinder ( $9 \%$ reduction in properties), the SR-0028 concave down and the SR-0027 concave up and down transverse flexural strength reductions range between 17 $22 \%$.

Ring tensile modulus was not measured for all of the specimens at elevated temperature because removing the extensometer from the split $D$ fixtures at an intermediate load would have interfered with the temperature in the test chamber. (It is necessary to remove the extensometer from the split D fixtures prior to the ultimate break load so that it is not destroyed when the ring fails.) Instead, one ring from the SR-0027 cylinder and two rings from the SR-0028 cylinder were tested with an extensometer to $12,000 \mathrm{lbs}(-205 \mathrm{ksi}$ ring tensile stress) to generate a load-deflection curve. The rings were then unloaded and set aside. The data from these specimens show no significant reduction in ring tensile modulus at $275^{\circ} \mathrm{F}$. This is as expected because ring tensile modulus is a fiber-dominated property.

\subsubsection{Composite DMA}

The purpose of this activity was to determine if the RS-14 resin in the T1000G/RS-14 composite was fully cured and, by inference, reached its maximum mechanical and thermal properties. Measuring the resin $\mathrm{T}_{\mathrm{g}}$ from a composite specimen by DMA may be a relatively simple method to evaluate the degree of cure. 
Table 4.6-1. Composite properties with temperature.

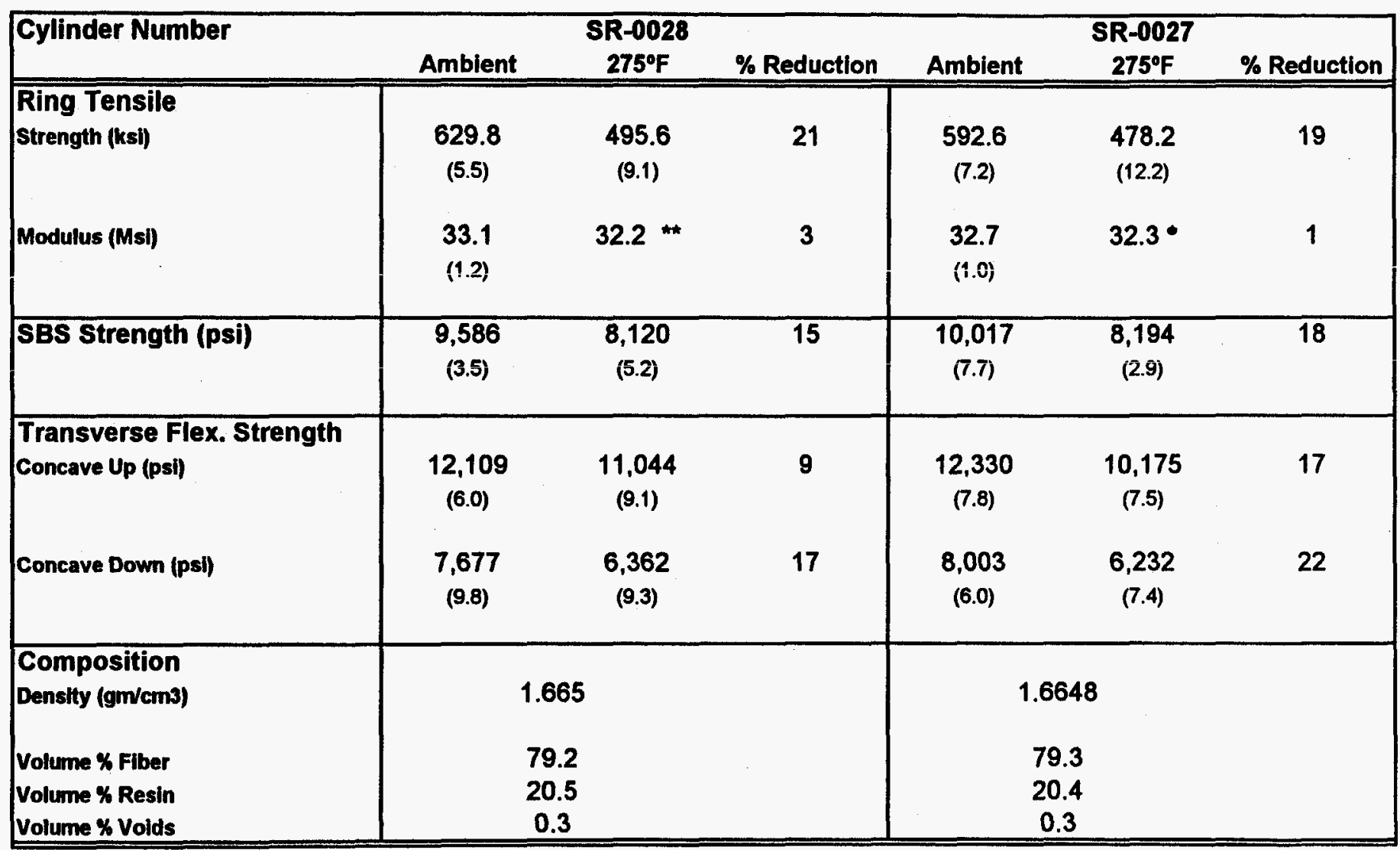

( ) Number in parentheses is percent coefficient of variation NA - Not available

Number of specimens: ring tensile (8-11); SBS strength (17-18); transverse flex. strength (10-11 each concave up and concave down)

* One specimen only *t Average of two specimens

SR-0028: $380^{\circ} \mathrm{F}$ precure; return to ambient temperature; ramp to $510^{\circ} \mathrm{F}$ postcure SR-0027: $380^{\circ} \mathrm{F}$ precure followed by ramp to $510^{\circ} \mathrm{F}$ postcure 
Figure 4.6.2-1 is the DMA result for a specimen cut from the SR-0019 composite process trial. The specimen was tested in the torsion rectangular test mode using a Rheometrics Dynamic Spectrometer. The torsion rectangular specimens were cut from sections of the cylinder so that the hoop fibers were perpendicular $\left(90^{\circ}\right)$ to the axis of the beam. The length of the specimens was along the cylinder's axial direction.

The $T_{g}$ data for the SR-0019 specimen is summarized in Table 4.6.2-1 along with data from a neat RS-14 panel measured as part of the RS-14 resin characterization activity (Sect. 3.2.3) for comparison. The $T_{g}$ data were derived by three methods: (1) the line-fit intersection method, (2) the $G^{\prime \prime}$ peak, and (3) the tan delta peak.

The data show that the $\mathrm{T}_{\mathrm{g}}$ data for the composite measured by all three methods are significantly lower than for the neat RS-14 panel. What is interesting is that the composite property data from the SR-0019 composite process trial were all reasonably high (Table 4.4-1), yet the $\mathrm{T}_{\mathrm{g}}$ of the composite's resin suggests that the matrix had not reached its maximum $T_{g}$. The reason for this is unknown. The contribution of the $\mathrm{T} 1000 \mathrm{G}$ fiber's sizing on composite thermal and mechanical properties has not been evaluated but may be a factor in these measurements.

\subsection{DISCUSSION}

The combination of ring tensile data collected during the composite process trial and reproducibility studies indicate that the RS-14 polycyanate resin has great potential as a matrix material for high strength wet-wound composite applications. The T1000G/RS-14 composite wetwinding process is reproducible and yielded cylinders with consistent compositions and ring tensile moduli over nine fabrications. Average ring tensile strengths of 630-650 ksi were achieved for several data sets, with some individual rings approaching $700 \mathrm{ksi}$ at failure. Transverse flexural and interlaminar shear strength averages are also respectable considering that these are high (78-80 volume percent) fiber content composites.

The data suggest that there is room for improvement in the processing of T1000G/RS-14 composite. Fiber strength translations achieved were on the order of $80-85 \%$. Increasing the fiber strength translation to the levels achieved with some epoxy systems (88-89\%) would increase the average ring tensile strength for T1000G/RS-14 composites to the $660-670 \mathrm{ksi}$ level. 
Figure 4.6.2-1. DMA of SR-0019 Composite.

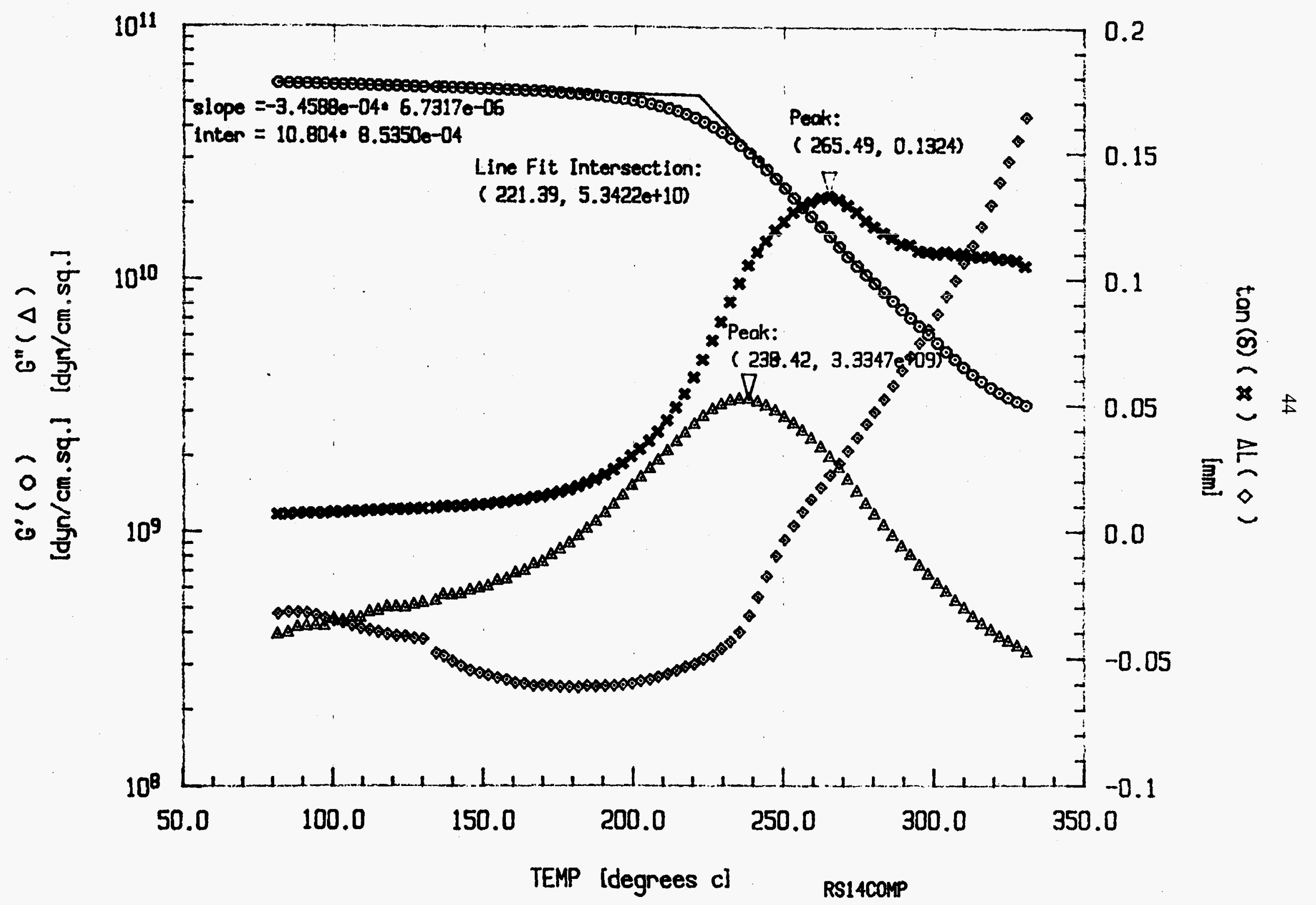


Table 4.6.2-1. Comparison of $\mathrm{Tg}$ from T1000G/RS-14 composite and RS-14 neat resin.

\begin{tabular}{|lccc|}
\hline \multicolumn{1}{|c}{ Description } & Method A & $\begin{array}{c}\mathrm{Tg}\left({ }^{\circ} \mathrm{F}\right) \\
\text { Method B }\end{array}$ & Method C \\
\hline \hline $\begin{array}{l}\text { T1000G/RS-14 composite } \\
\text { (SR-0019 process trial) }\end{array}$ & 430 & 461 & 510 \\
$\begin{array}{l}\text { RS-14 neat resin } \\
\text { (Panel 348) }\end{array}$ & 512 & 518 & 536 \\
\hline
\end{tabular}

Method A: Line-fit intersection ( $\mathbf{G}^{\prime}$ )

Method B: G" peak

Method C: Tan delta peak 
The results obtained during the composite process trials study mirror the results obtained in the RS-14 resin characterization study in several ways: The highest neat resin tensile strengths, resin elongations, composite ring tensile strengths, and concave up transverse flexural strengths were obtained using a cure cycle that included a $270^{\circ}$ or $380^{\circ} \mathrm{F}$ precure step followed by a prompt ramp to the $510^{\circ} \mathrm{F}$ postcure temperature. Variants of this cure cycle yielded reductions of $7-10 \%$ in average ring tensile strength. This may not be significant, however, because based on the limited data of this study the variability of ring tensile data from cylinders cured using the same cure schedule can also be as high as $7 \%$.

The source(s) of this variability are presently not well understood. The summary section of the RS-14 resin characterization study notes that the thermal and mechanical properties of the RS-14 resin were also variable and seem to depend on the right set of conditions (cure temperature, environment, rate of reaction) to achieve optimum properties. In particular, less-than-optimum cure resulted in a low $\mathrm{T}_{\mathrm{g}}$ matrix with a lower tensile strength and percent elongation. It is reasonable to expect that the best $\mathrm{T} 1000 \mathrm{G}$ fiber strength translations would be achieved when the resin has a high strain-to-failure, which for RS- 14 is approximately $4 \%$ when cured properly. Less-than-optimum cures yielding strain-to-failures on the order of $2-3 \%$ would be inadequate to accommodate the nominal $2.1 \%$ elongation of the $\mathrm{T} 1000 \mathrm{G}$ fiber, resulting in poor fiber strength translations and lower hoop tensile strengths.

This variability in the neat resin and composite properties suggest that the impact of reaction rate, or cure kinetics, as well as the environment (for example, the presence of moisture) should be investigated to better understand their impact on the cyclotrimerization chemistry and ultimately the thermal and mechanical properties of the RS-14 resin. A better understanding of the factors that control the polycyanate cure reaction may provide insight into procedures for improving the composite's properties and reducing variability.

Both the neat resin data in Tables 3.2.1-1, 3.2.1-2 and the composite data in Table 4.4-1 showed that multiple postcure cycles in air significantly reduced the neat resin tensile strength, resin elongation, and the composite ring tensile strength. These data suggest that postcure cycles should be performed in an inert atmosphere to avoid oxidation and degradation of the resin surface. This is particularly true if multiple postcure cycles are performed. 
Because the data of the neat resin and composite samples that received multiple postcure cycles are obscured by the fact that the RS-14 resin is subject to surface oxidation and degradation when heated to high temperatures in air, this portion of the study should be repeated with the exception that the postcure cycles be performed in an inert atmosphere. Eliminating the oxidation damage will make it possible to determine the true effects of multiple postcure cycles on RS-14 resin properties. This information holds significance for thick composite hardware where it may be desirable to wind and cure the wall thickness in multiple fabrication stages.

\section{CONCLUSIONS AND RECOMMENDATIONS}

The following is a summary of conclusions and recommendations from the T1000G lot characterization, RS-14 resin characterization and the composite process trial sections of this report:

The T1000G fiber (Lot No. 615022) procured for this study had a measured average tensile strength of $954 \mathrm{ksi}$. This is higher than what ORNL/ORCMT has measured to date with other T1000G fiber lots and is also higher than the average lot tensile strength Toray quoted for this material (930 ksi). This same lot has an average tensile modulus of $40.5 \mathrm{Msi}$ as measured and calculated by ORNL/ORCMT which is comparable to other previously sampled lots of T1000G. The measured average elongation of this lot is $2.1 \%$ and the average weight per unit length is 0.488 $\mathrm{g} / \mathrm{m}$. The elongation and weight per unit length data are comparable to Toray's measurements.

Through-spool variability appears to be about the same magnitude as the spool-to-spool variability encountered at both ends of the carbon fiber packages. It is recommended that a statistical analysis be conducted on the fiber strength data obtained in the T1000G lot characterization study. The analyses should investigate strength variability on a spool-to-spool and through-spool basis. This information may give the composites design community a baseline for establishing a quality assurance program for specifying fiber procurements.

The isothermal viscosity data confirm that the RS-14 resin is an excellent wet-winding resin in the vicinity of $170^{\circ} \mathrm{F}$ because of its low viscosity ( 0.53 poise) and stability (eight hours minimum at this temperature). The minimum temperature needed to gel RS-14 resin in a four hour period is 
in the vicinity of $260^{\circ} \mathrm{F}$. The RS- 14 resin gels quickly (less than an hour) when the temperature is in the vicinity of $310^{\circ} \mathrm{F}$.

When properly cured, the neat RS-14 resin is capable of a minimum 11,000 psi tensile strength and a strain-to-failure that is on the order of $4 \%$ or higher. The resin tensile modulus (determined from the initial slope of the load-deflection curve) is between $410-430 \mathrm{ksi}$ and its shear modulus is between $150-160 \mathrm{ksi}$.

Less than optimum cure results in the RS-14 resin system having a lower $T_{g}$, lower tensile strength, and lower strain-to-failure. The best set of neat RS-14 resin thermal and mechanical properties were obtained from panels that had been postcured at $510^{\circ} \mathrm{F}$. Multiple postcure cycles in air, however, significantly reduced the neat resin tensile strength and resin elongation. Degradation of the surface resin layer from oxidation is believed to be a contributing factor.

The highest neat resin tensile strengths, resin elongations, composite ring tensile strengths, and concave up transverse flexural strengths were obtained using a cure cycle that included a $270^{\circ} \mathrm{F}$ or $380^{\circ} \mathrm{F}$ precure step followed by a prompt ramp to the $510^{\circ} \mathrm{F}$ postcure temperature. An "interrupted" cure cycle (for example, returning to ambient temperature after the precure step before ramping to the postcure temperature) yielded significantly lower neat resin tensile strengths, resin elongations, and composite ring tensile strengths. By-passing the precure step and ramping directly to the postcure temperature yielded significantly lower neat resin tensile strengths, resin elongations, and composite ring tensile strengths.

The ORNL/ORCMT T1000G/RS-14 wet-winding process yielded cylinders with reproducibly high fiber fractions between 78-80 volume percent. The void level was less than 0.5 volume percent. The ring tensile modulus for these fiber fractions was reproducible and in the range of 32.2 to 33.1 Msi.

Typical T1000G fiber strength translations in composite ranged between 81 to $85 \%$. The two highest sets of T1000G/RS-14 composite ring tensile strength data obtained in this study averaged 631 and $650 \mathrm{ksi}$. The fiber strength translations for these sets are on the order of 84-86\%. Both cylinders were fabricated with a $270^{\circ}$ or $380^{\circ} \mathrm{F}$ precure followed by a prompt ramp to the $510^{\circ} \mathrm{F}$ postcure temperature. The highest individual ring tensile strength recorded in this study was $696 \mathrm{ksi}$. 
There was little correlation observed between cure cycle, ring tensile strength, and interlaminar shear strength. The cylinder with the highest ring tensile strength had one of the lower interlaminar shear strength values. Interlaminar shear strength data set averages ranged between 8,856 to $10,857 \mathrm{psi}$.

The highest sets of concave up transverse flexural strength data obtained in this study averaged $14,077 \mathrm{psi}$ and $14,250 \mathrm{psi}$. Both cylinders were fabricated with a $380^{\circ} \mathrm{F}$ precure followed by a prompt ramp to the $510^{\circ} \mathrm{F}$ postcure temperature. The concave up transverse flexural strengths of other cylinders fell in the range of 11-13 ksi. There was no correlation observed between cure cycle and concave down transverse flexural strength; the data set averages ranged between 6800 7900 psi.

Significant degradation of ring tensile strength occurred in cylinders that received two additional postcure cycles in air. Degradation occurred both when the cylinder was supported by the mandrel or was unsupported (free-standing). In one trial, the concave down transverse' flexural strength of the cylinder that was supported on the mandrel was almost half the value measured for cylinders that were postcured only once. However, composite cylinders receiving two additional postcure cycles in air while supported on the mandrel experienced no degradation in concave up transverse flexural strength or interlaminar shear strength.

In terms of elevated temperature performance, reductions in RS-14 neat resin tensile strength and modulus at $275^{\circ} \mathrm{F}$ were on the order of 17 and $25 \%$, respectively. Reductions in composite ring tensile strength, interlaminar shear strength and concave up and down transverse flexural strength for hoop-wound T1000G/RS-14 composite were also on the order of $20 \%$ at $275^{\circ} \mathrm{F}$. Ring tensile modulus was not affected at this temperature, primarily because it is a fiber-dominated property.

Areas of investigation or future study stemming from the conclusions in this report focus on the processing characteristics of the RS-14 polycyanate resin. In particular, the impact of reaction rate, (or cure kinetics) and environment (such as moisture) should be investigated to better understand their significance to the cyclotrimerization chemistry and ultimately the RS-14 resin's thermal and mechanical properties. This information may hold the key to reducing variability in the final (composite) product. 
The results obtained for neat RS-14 resin and T1000G/RS-14 composite cylinders exposed to multiple elevated temperature cycles suggest that elevated temperature processing should be performed in an inert atmosphere to prevent oxidation and degradation at the resin surface. Determination of the minimum threshold at which degradation occurs as well as whether it can be eliminated by processing in an inert atmosphere are both areas for future investigation.

The study to investigate the effects of multiple postcure cycles on RS-14 resin and composite should be repeated with the exception that all of the postcure cycles are performed in an inert atmosphere. Eliminating the oxidation damage will make it possible to determine the true effects of multiple postcure cycles on RS-14 properties. This work is necessary to support the fabrication of thick, stage-cured composite hardware.

\section{REFERENCES}

1. B. J. Frame and J. M. Starbuck, Preliminary Investigation of Polycyanate Resins for WetFilament Wound High-Strength Composites, SAMPE, Covina, California, 1996.

2. D. A. Shimp and S. J. Ising, Moisture Effects and Their Control in the Curing of Polycyanate Resins, PMSE Division, ACS National Meeting, San Francisco, California, 1992.

\section{ACKNOWLEDGMENTS}

The author wishes to acknowledge and thank J. V. LaForge and W. G. Dodge for their contributions toward the design and manufacture of the internally heated steel mandrel. Special thanks are also extended to C. L. Knaff, D. Skidmore, T. D. Thompson and K. D. Yarborough for their participation in the sample fabrication and preparation performed for this study. 
APPENDIX A. DMA RESULTS OF ISOTHERMAL VISCOSITY TESTS 
$\eta *(0)$

[P]

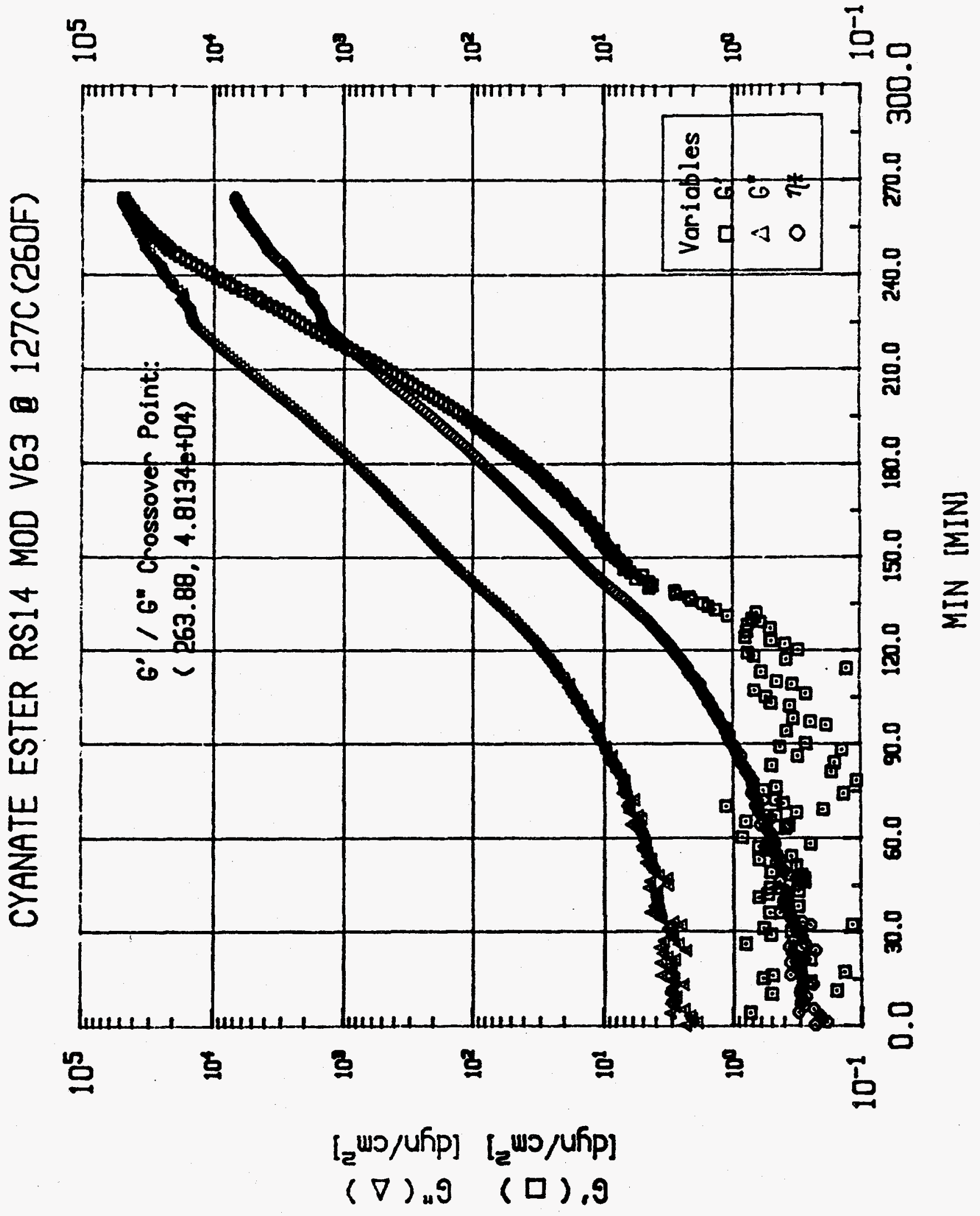


[P]

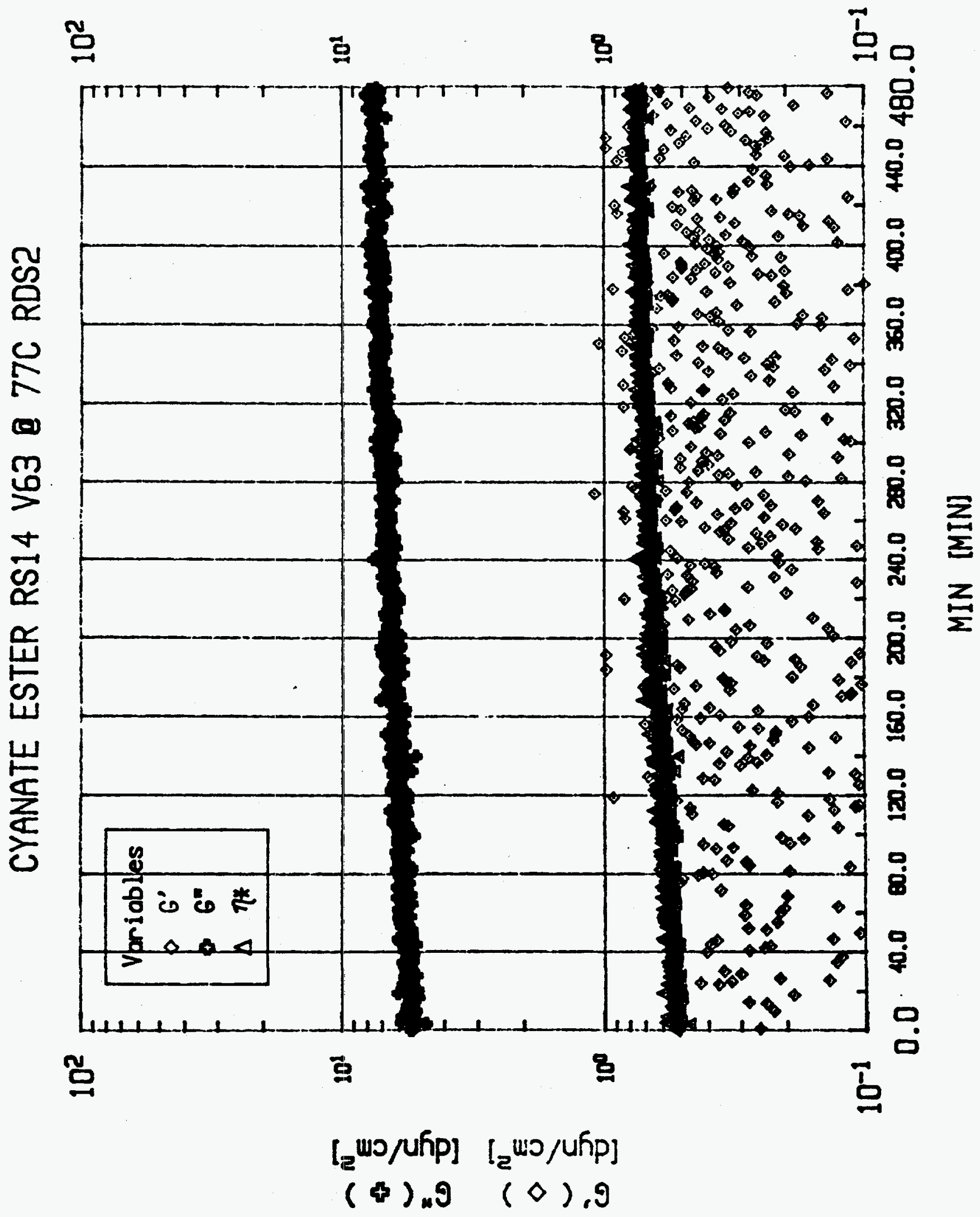


$\eta *(\Delta)$

[P]

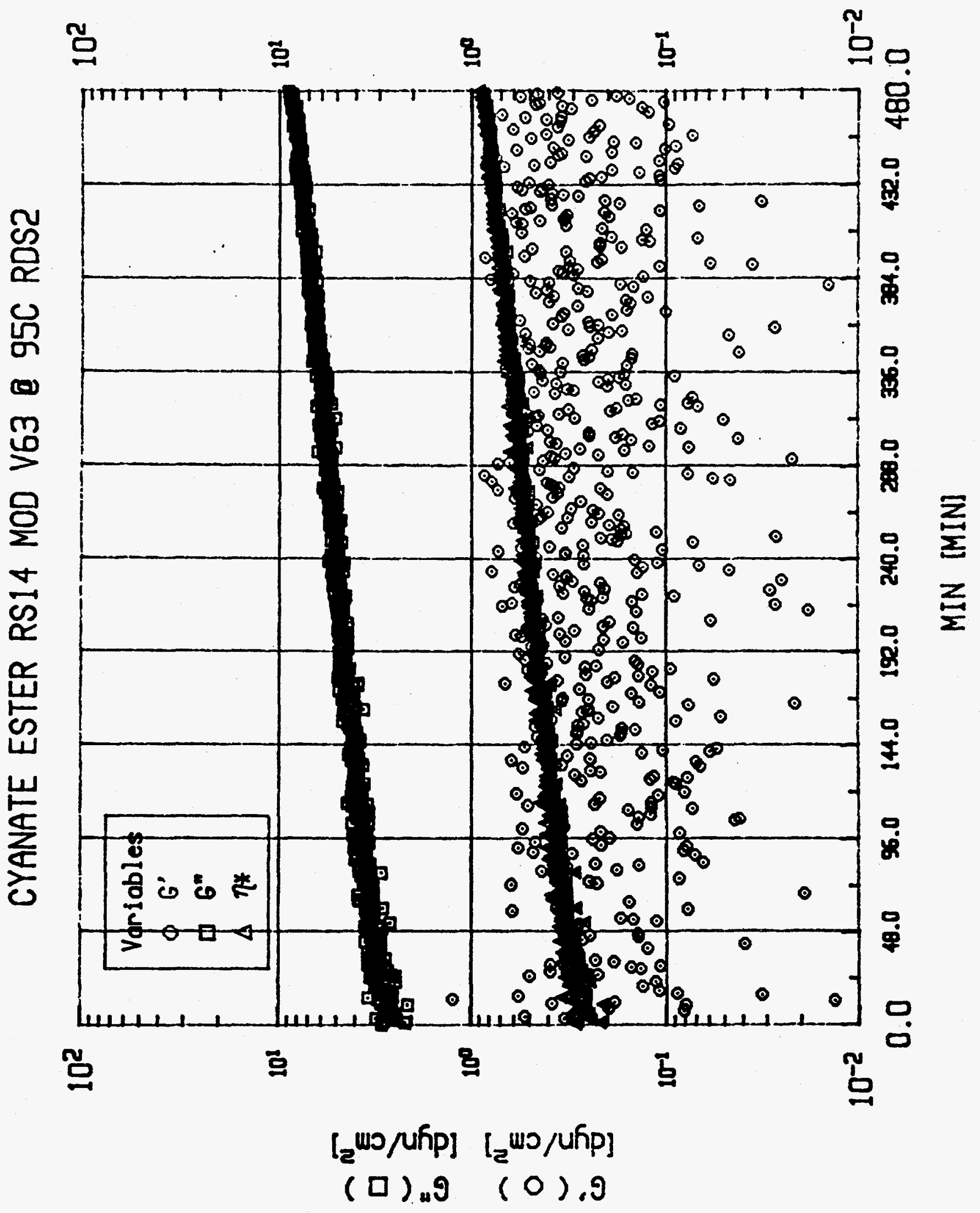


CYANATE ESTER RS14 MOD V63 O110C (23OF)

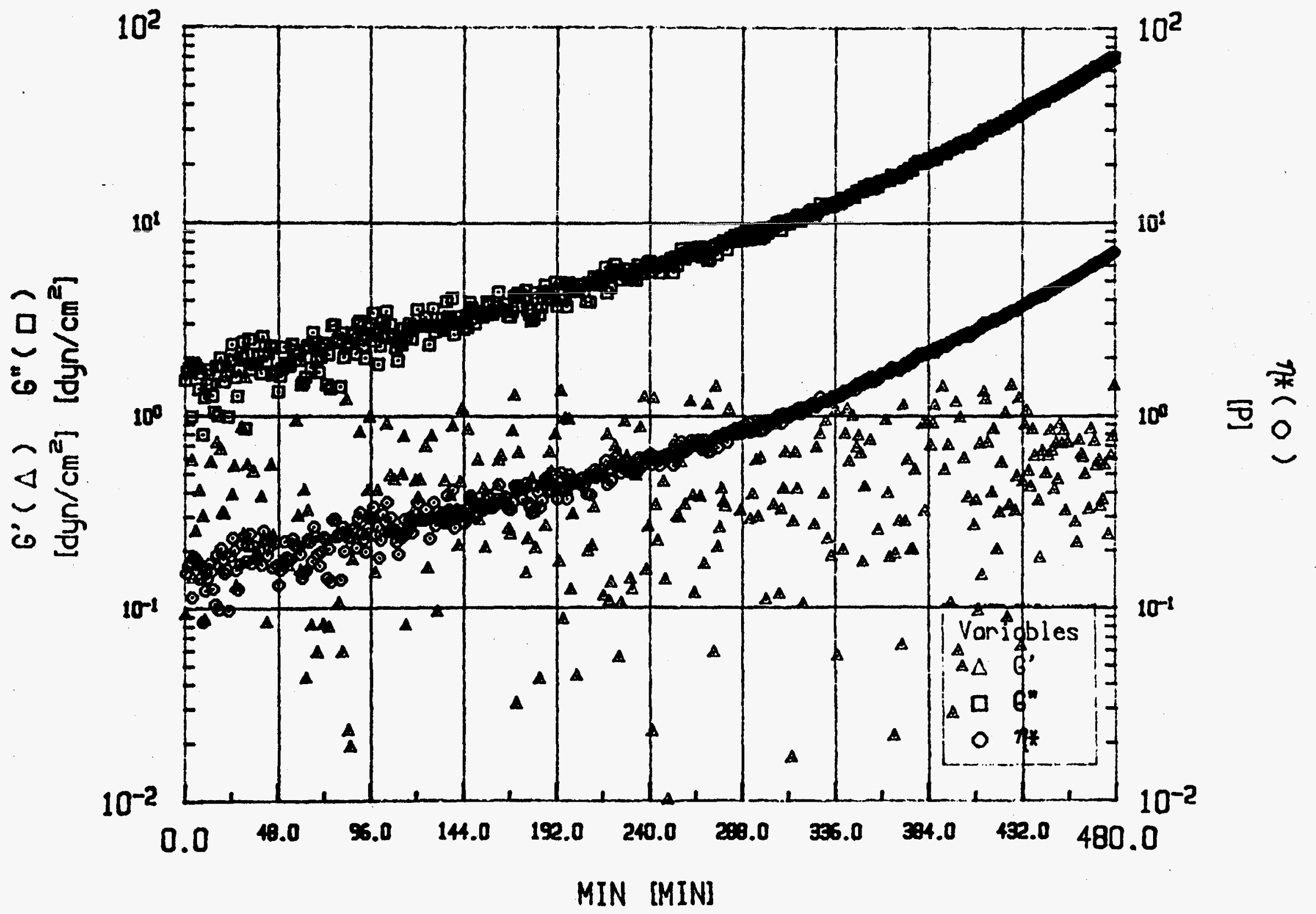


CYANATE ESTER RS14 MOD V63 O 155C RDA2

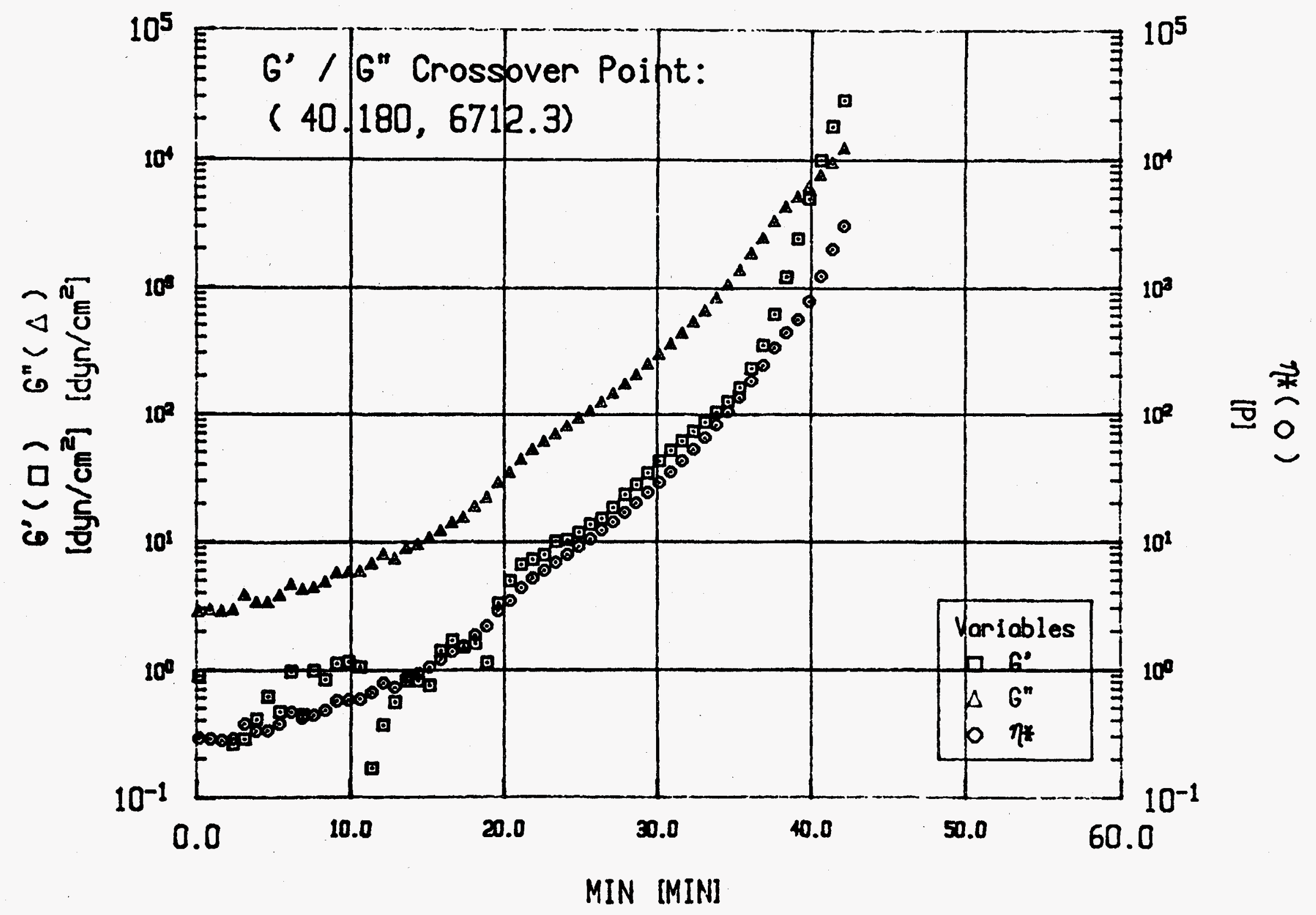


CYANATE ESTER RS14 MOD V63 O 144C RDS2

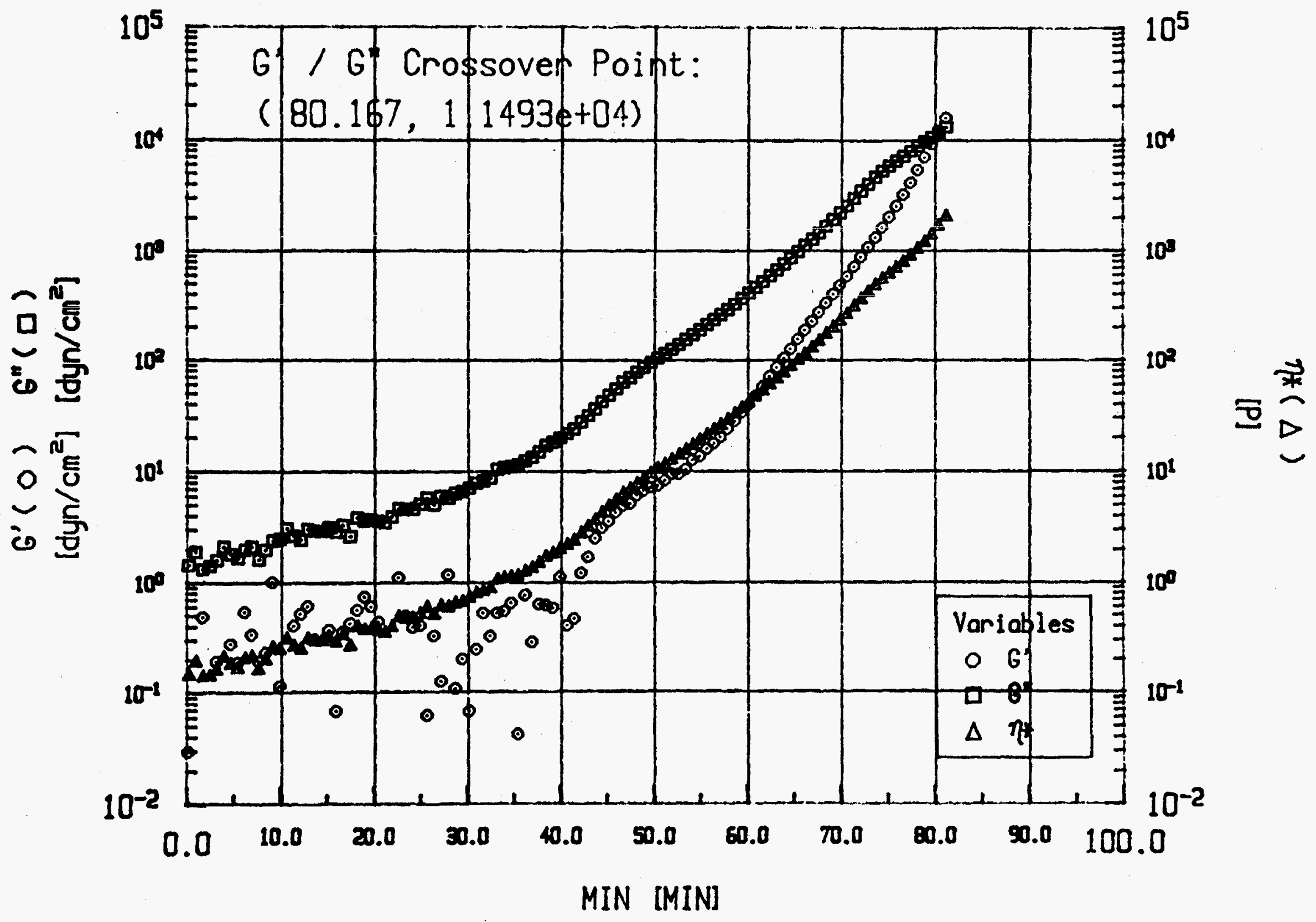


APPENDIX B. DMA RESULTS FOR NEAT RESIN PANELS 
$\tan (\delta)(-)$

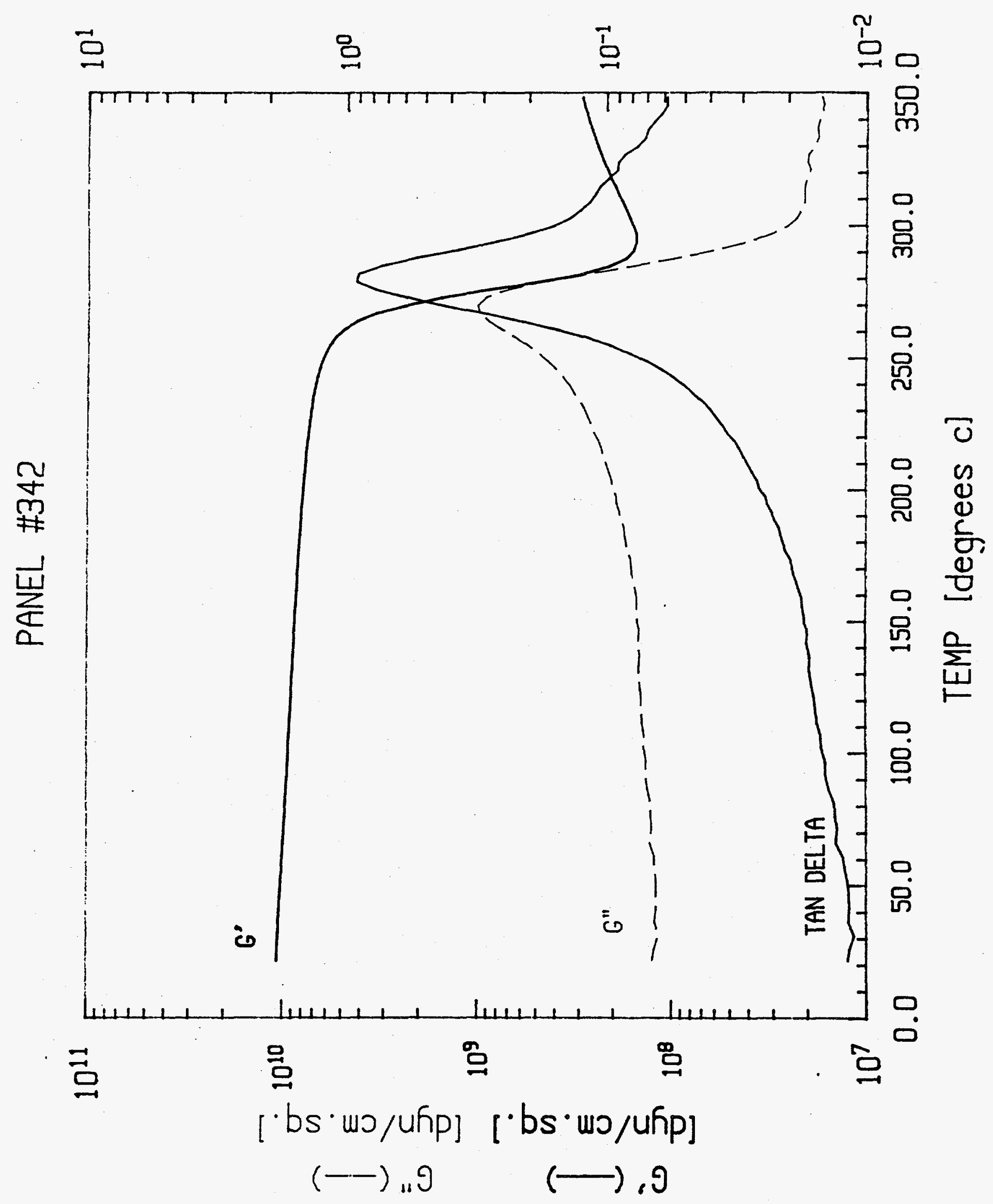


$\tan (\delta)(-)$

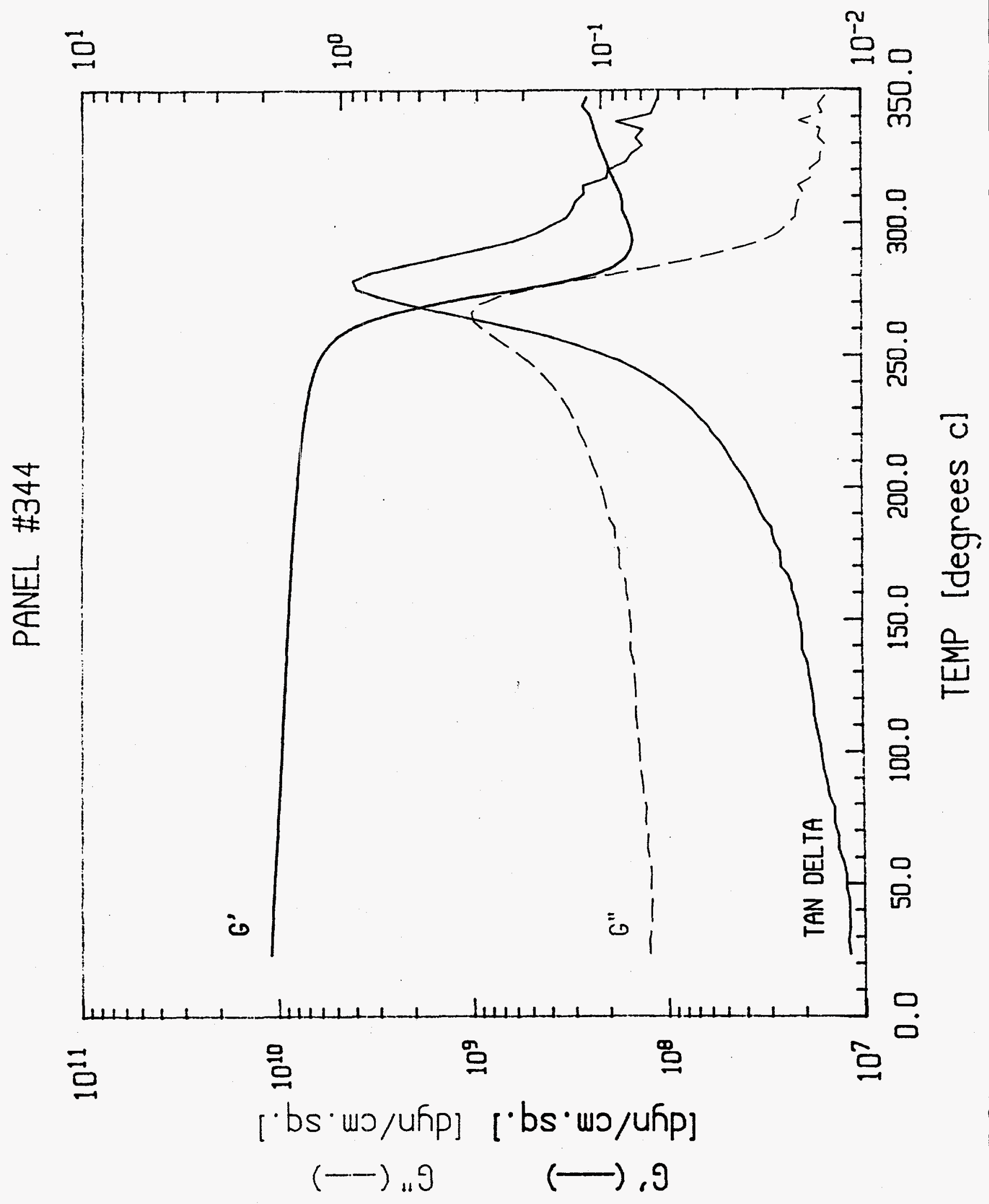


$\tan (\delta)(\longrightarrow)$

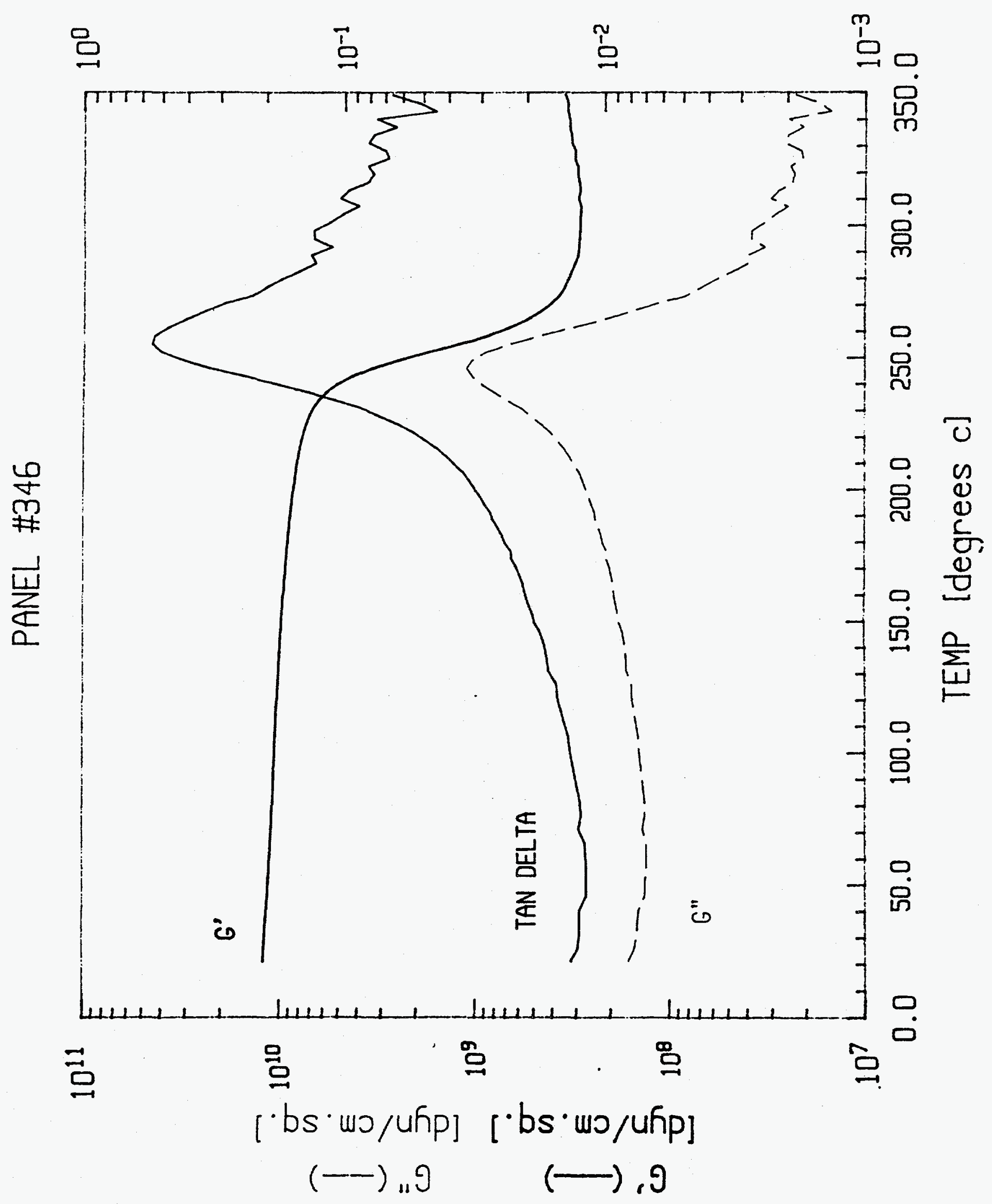


$\tan (\delta)(-)$

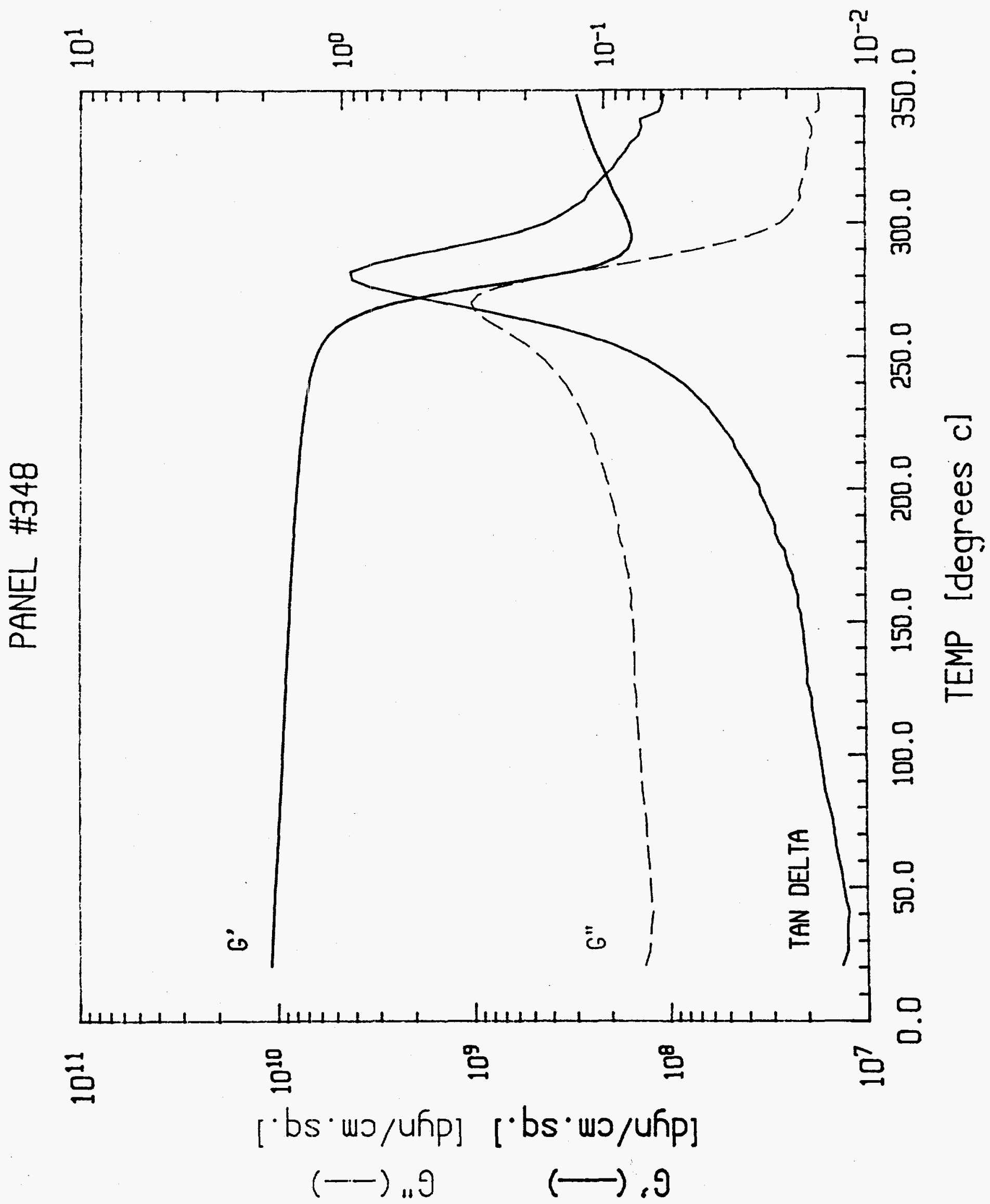


$\tan (\delta)(\longrightarrow)$

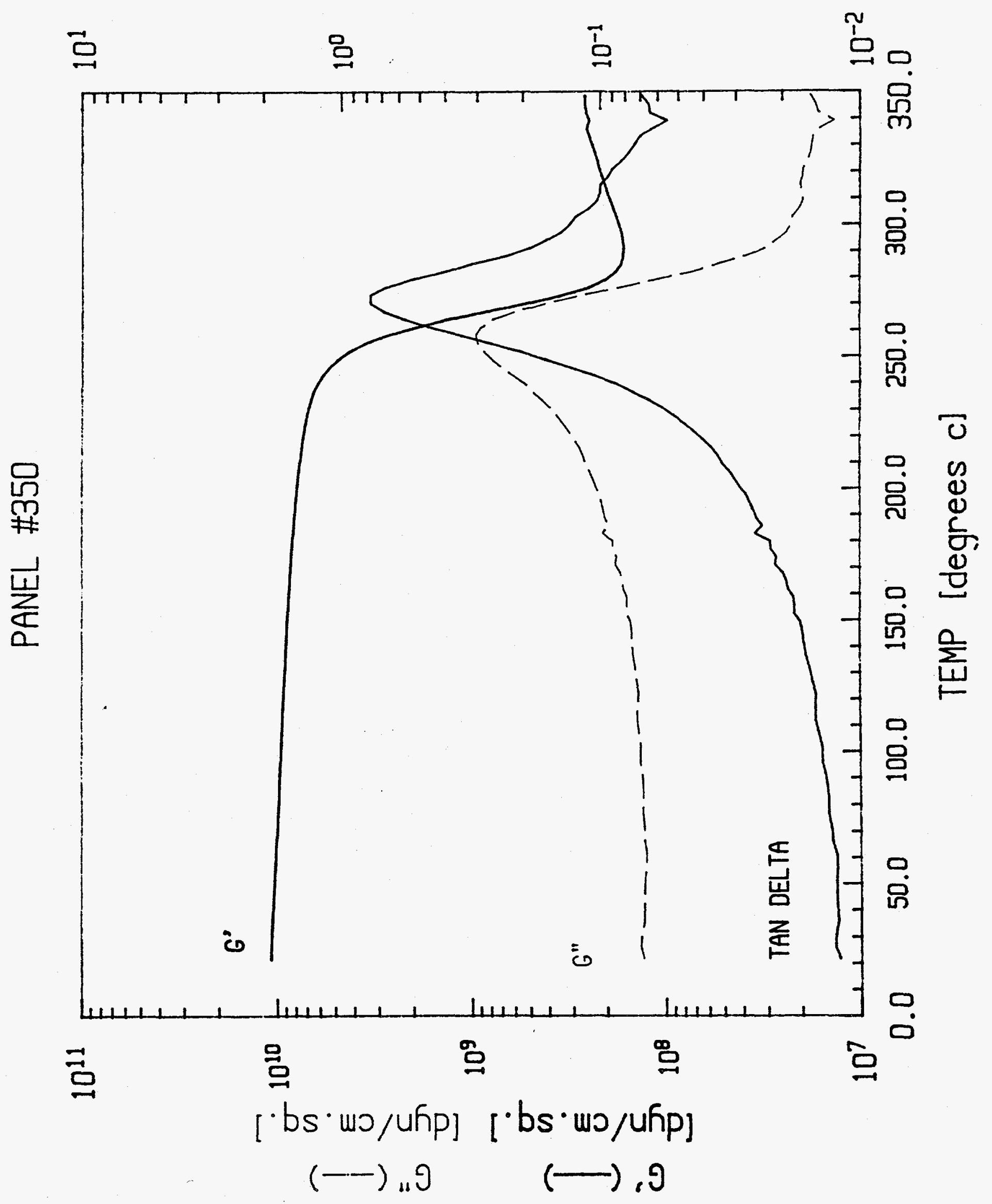


$\tan (\delta)(-)$

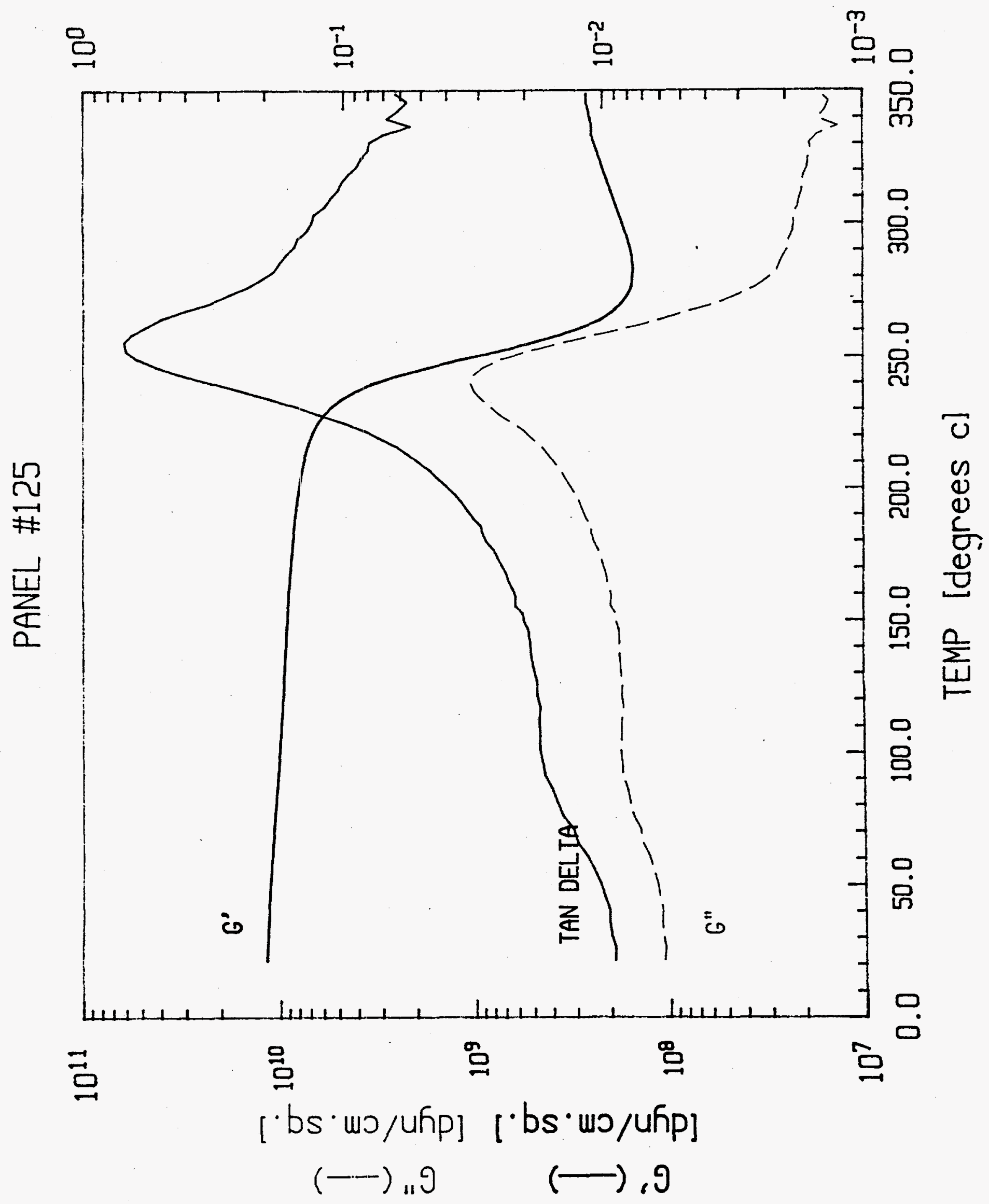


$\tan (\delta)(\longrightarrow)$

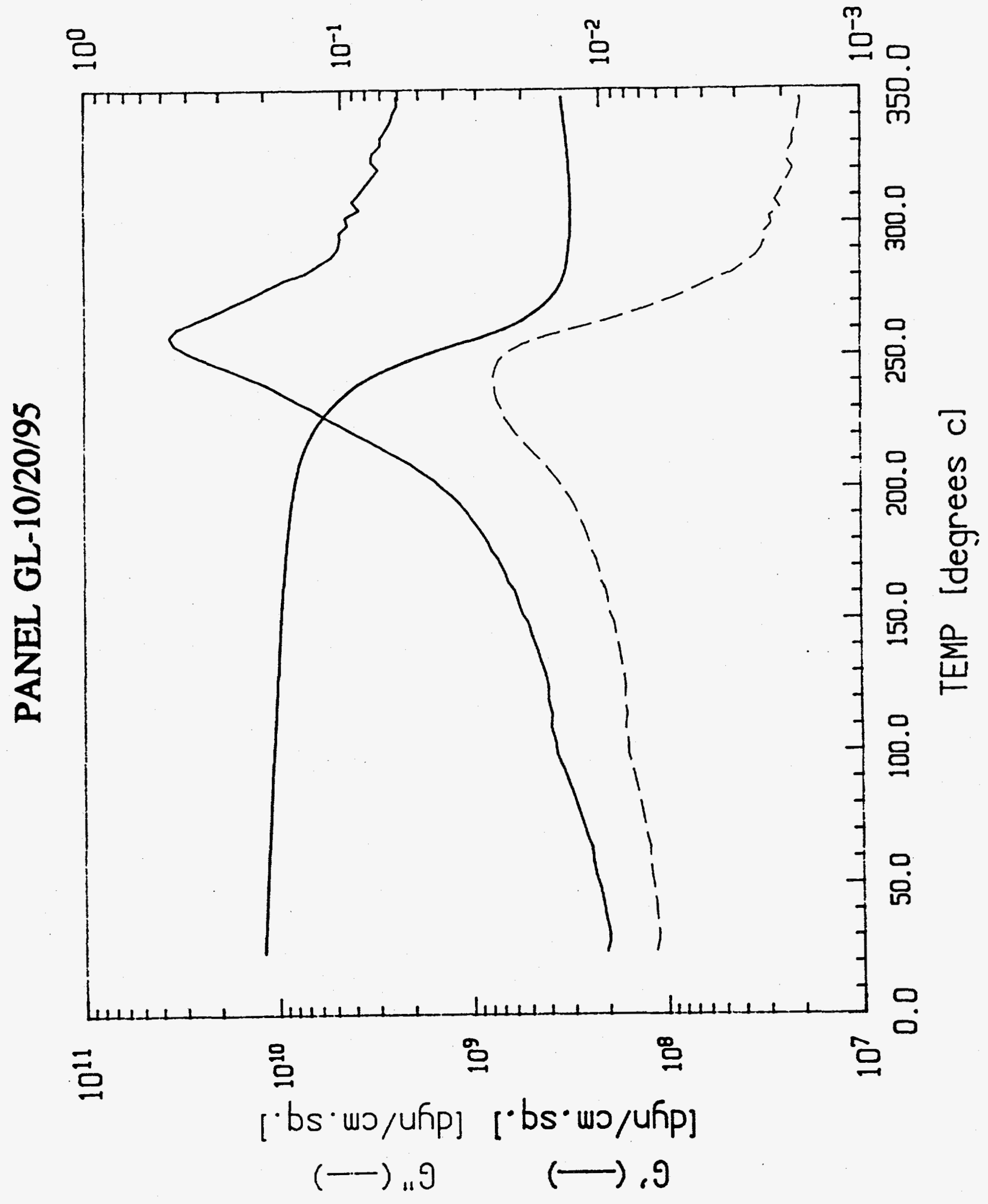




\section{DISTRIBUTION}

Lockheed Martin Energy Research Corporation

H. W. Blake

R. G. Boeman

J. L. Cook

J. M. Corum

W. G. Dodge

E. C. Fox

B. J. Frame (20)

R. G. Gilliland

J. G. Hansen (15)

C. J. Janke

J. V. LaForge

R. E. Leach

C. F. Leitten, Jr.

S. R. McNeany

R. E. Norris

F. L. Paulauskas

J. T. Shaffer

J. M. Starbuck

G. E. Wrenn, Jr.

Central Research Library

Laboratory Records - RC

Office of Scientific and Technical Information (2) 